\title{
Hydrothermal Liquefaction of Water Hyacinth: Effect of Process Conditions and Magnetite Nanoparticles on Biocrude Yield and Composition
}

\author{
Dan Egesa*, Patrick Mulindwa, Edward Mubiru, Hilda Dinah Kyomuhimbo, Godwin Aturagaba \\ Industrial Chemistry Section, Department of Chemistry, School of Physical Sciences, College of Natural Sciences, \\ Makerere University, Kampala, Uganda \\ Email: ^dan.egesa@mak.ac.ug
}

How to cite this paper: Egesa, D., Mulindwa, P., Mubiru, E., Kyomuhimbo, H.D. and Aturagaba, G. (2021) Hydrothermal Liquefaction of Water Hyacinth: Effect of Process Conditions and Magnetite Nanoparticles on Biocrude Yield and Composition. Journal of Sustainable Bioenergy Systems, 11, 157-186.

https://doi.org/10.4236/jsbs.2021.114012

Received: August 30, 2021

Accepted: October 12, 2021

Published: October 15, 2021

Copyright $\odot 2021$ by author(s) and Scientific Research Publishing Inc. This work is licensed under the Creative Commons Attribution International License (CC BY 4.0).

http://creativecommons.org/licenses/by/4.0/

\begin{abstract}
In this work, an efficient way of converting the water hyacinth to biocrude oil using magnetite nanoparticles (MNPs) as potential catalysts was demonstrated for the first time. MNPs were synthesised by co-precipitation and used in the hydrothermal liquefaction (HTL) of water hyacinth at different reaction conditions (temperature, reaction time, MNPs to biomass ratio and biomass to water ratio). The best reaction conditions were as follows: temperature$320^{\circ} \mathrm{C}$, reaction time -60 minutes, MNPs to biomass ratio $-0.2 \mathrm{~g} / \mathrm{g}$ and biomass to water ratio $-0.06 \mathrm{~g} / \mathrm{g}$. HTL in presence of MNPs gave higher biocrude yields compared to HTL in absence of MNPs. The highest biocrude yield was $58.3 \mathrm{wt} \%$ compared to $52.3 \mathrm{wt} \%$ in absence of MNPs at similar reaction conditions. The composition of biocrude oil was analysed using GC-MS and elemental analysis. GC-MS results revealed that HTL in presence of MNPs led to an increase in the percentage area corresponding to hydrocarbons and a reduction in the percentage area corresponding to oxygenated compounds, nitrogenated compounds and sulphur compounds. Elemental analysis revealed an increase in the hydrogen and carbon content and a reduction in the nitrogen, oxygen and sulphur content of the biocrude when HTL was done in presence of MNPs compared to HTL in absence of MNPs. The nanoparticles were recovered from the biochar by sonication and magnetic separation and recycled. The recycled MNPs were still efficient as HTL catalysts and were recycled five times. The application of MNPs in the HTL of water hyacinth increases the yield of biocrude oil, improves the quality of biocrude through removal of hetero atoms, oxygen and sulphur compounds and is a potentially economical alternative to the traditional petroleum catalysts since MNPs are
\end{abstract}


cheaper, widely available and can be easily recovered magnetically and recycled. This will potentially lead to an economical, environmentally friendly and sustainable way of producing biofuels from biomass.

\section{Keywords}

Hydrothermal Liquefaction, Water Hyacinth, Magnetite Nanoparticles, Biocrude Oil

\section{Introduction}

The ever-increasing global energy demand has encouraged heavy dependence on petroleum derived fuels as a major source of energy. This could result in irreversible damage to the environment due to release of toxic chemicals and greenhouse gases into the atmosphere. The global carbon-dioxide levels are constantly increasing currently standing at $415 \mathrm{ppm}$ from $279 \mathrm{ppm}$ in 1750 [1]. Atmospheric $\mathrm{CO}_{2}$ is increasing at a rate of 34 gigatons per year [2]. Moreover, the depletion of fossil fuels is inevitable due to reduction in conventional crude oil production since 2004 when it was at its peak at 74 million barrels per day [3]. These challenges have encouraged research into alternative sources of clean, renewable and sustainable energy such as biofuels.

Biofuels are produced mostly from first generation feedstock like sugarcane, corn and soybean. However, competition between fuel and food for the limited food sources has proved to be a major drawback. Meanwhile, second generation feedstock from non-food sources using energy plants such as Jatropha have been an improvement, but these too have limitations due to competition for good quality agricultural land with food crops [4]. The water hyacinth and algae fall under third generation feedstock. These are a promising alternative because they grow fast due to their efficiency in photosynthesis, they can double their biomass in 24 hours [5] and can be cultivated on large water bodies hence no competition for fertile agricultural land [6].

Some of the techniques employed to convert biomass to biofuels include: 1) transesterification which converts the extracted lipids (triglycerides or free fatty acids) to the fatty acid methyl esters (biodiesel), 2) pyrolysis: In pyrolysis, the biomass is heated in absence of oxygen to produce bio-oils, which are upgraded to gasoline, diesel and kerosene, 3) gasification: in gasification, biomass is converted to syngas, then syngas is catalytically converted to alcohols or to diesel via the Fischer-Tropsch process and 4) Hydrolysis of carbohydrates from the biomass to sugars, then fermentation of the sugars to bio-ethanol.

A more promising route to biofuel production is the hydrothermal liquefaction (HTL) process. The HTL process is a wet thermochemical conversion process in which wet biomass with a water content of $75 \%$ to $95 \%$ is converted to biocrude oil, at temperatures ranging between $300^{\circ} \mathrm{C}-375^{\circ} \mathrm{C}$ and pressures between 40 - 200 bars [7]. 
The bio-crude oil can then be upgraded to gasoline, diesel and kerosene. Since wet biomass is used, it eliminates the need for drying biomass making the process energy efficient. The HTL process uses less than $5 \%$ of the total energy used in the biomass drying step of solvent extraction [8]. The HTL process uses water as a reactive medium to convert biomass into liquid crude oil under controlled conditions. In this conversion, the main cellular constituents such as lipids, proteins and carbohydrates are broken down at the high temperatures and pressures. This coupled with hydrolytic attack leads to breakage of biomolecules in the hot compressed water resulting in the production of a biocrude oil [9] with a reasonably high calorific value [10]. Life cycle and techno economic analysis shows that the overall HTL process uses less energy than extraction and transesterification of lipids [11] though more work is needed to increase the biocrude yields and quality. To this end, effort has been invested in investigating the effect of catalysts on the HTL process and its ability to produce higher quality products [12].

Solid nanocatalysts have shown great catalytic potential because they possess large chemically active surface areas and have high chemical and physical stability [12]. These are paramount properties for industrial applications. However, recovery of solid catalysts from the biocrude oil mixture by filtration is a major challenge in their application and it is not economically viable. Therefore, it is important to develop heterogeneous catalysts which can be recovered and recycled easily for further applications in HTL reactions. An interesting potential candidate for this application are magnetite based nanocatalysts because they can easily be recovered magnetically and recycled thereby improving their life span and cost effectiveness. In addition, they possess a high catalytic activity for bio-catalysis, phase transfer catalysis and photocatalysis [13]. Furthermore, they possess a high catalytic activity and large specific surface areas. Despite their catalytic potential, no study has yet demonstrated their catalytic effect on the yield and chemical composition of biocrude oil in the hydrothermal liquefaction of water hyacinth.

Therefore, this work focuses on the investigation of the catalytic effect of magnetite nano particles on the yield and quality of biocrude oils in the HTL of water hyacinth. The water hyacinth was chosen because it is an invasive species on fresh water bodies in Uganda and there is very little work on its catalytic conversion to biofuels. In Uganda, the invasion of the water hyacinth on freshwater bodies has disrupted water transport and hydropower generation, reduced the fish catch and polluted freshwater. Lake Victoria alone has been invaded at a rate of 6300 tonnes per day [14]. Its effects have led to reduction in fish exports hence reduced income to the country. In addition, the increase in industrialisation has resulted in increased energy demand for many developing countries hence the need to increase the energy base of these countries. A potential alternative to this challenge is the production of biofuels from the abundant and environmentally problematic water hyacinth through the HTL process. The objectives of this research are: 1) to produce biocrude oil from the water hyacinth through the hydrothermal liquefaction process, 2) to investigate the effect of 
HTL process conditions on the yield and quality/composition of biocrude oil and 3) to investigate the catalytic effect of MNPs on the yield and chemical composition of the biocrude oil. This work therefore presents for the first the application of magnetite nanoparticles in the catalytic HTL of the water hyacinth. Magnetite nanoparticles were chosen because they have shown positive results in the catalytic HTL of algae [15]. Some of the differences between water hyacinth and algae are in their composition. Algae has a higher protein content (about 63\%) than water hyacinth while the water hyacinth contains more cellulose and lignin. Because of these differences, different reaction pathways are undertaken resulting in production of different quantities of compounds as seen in the results section. Conversion of water hyacinth to biofuel would potentially reduce the negative consequences caused by the water hyacinth as well as contribute to the production of clean, renewable and environmentally friendly liquid fuels hence contributing to the energy needs of the country.

\section{Materials and Methods}

\subsection{Materials}

Hexa-hydrate ferrous chloride $\left(\mathrm{FeCl}_{3} \cdot 6 \mathrm{H}_{2} \mathrm{O}\right)$, tetra-hydrate ferrous chloride (Fe$\left.\mathrm{Cl}_{2} \cdot 4 \mathrm{H}_{2} \mathrm{O}\right)$, Ammonium hydroxide $\left(\mathrm{NH}_{4} \mathrm{OH}\right)$, hydrochloric acid $(\mathrm{HCl})$, dichloromethane, sodium hydroxide $(\mathrm{NaOH})$, acetone and ethanol were purchased from Laboratory needs solutions in Kampala Uganda. All chemicals used were of analytical grade. All solutions were prepared using de-ionized water. The water hyacinth was obtained from the shores of Lake Victoria at Gaba beach. The typical composition of the water hyacinth biomass is as follows: cellulose (18\%-31\%), hemicellulose $(18 \%-43 \%)$, lignin $(7 \%-26 \%)$, protein (average of $7.11 \%)$ and fat (average of 1.9\%) among other constituents [16] [17].

\subsection{Methods}

\subsubsection{Synthesis of Magnetite Nanoparticles}

Magnetite nanoparticles (MNPs) were synthesized by co-precipitation method. In this method, hexahydrate ferrous chloride $\left(\mathrm{FeCl}_{3} \cdot 6 \mathrm{H}_{2} \mathrm{O}\right) 5.4 \mathrm{~g}$ and tetrahydrate ferrous chloride $\left(\mathrm{FeCl}_{2} \cdot 4 \mathrm{H}_{2} \mathrm{O}\right) 2.0 \mathrm{~g}$ were dissolved in $25 \mathrm{~cm}^{3}$ of de-ionised deoxygenated water. This solution was then added dropwise to $200 \mathrm{~cm}^{3}$ of deoxygenated 1.5 molar ammonium hydroxide $\left(\mathrm{NH}_{4} \mathrm{OH}\right)$ solution with vigorous stirring at $300 \mathrm{rpm}$ for 2 hours. A black precipitate was immediately formed and it was decanted from the solvent magnetically. The precipitate was then washed with deoxygenated de-ionized (DI) water and ethanol to neutralize residual ions and dried under vacuum conditions at $60^{\circ} \mathrm{C}$ for $4-6$ hours. The dried sample was kept under $\mathrm{N}_{2}$ to prevent oxidation and for later use in the catalytic HTL reactions.

\subsubsection{Biomass Processing}

The water hyacinth was harvested at the shores of Lake Victoria in Gaba, washed with distilled water and cut into small pieces (both leaves and stems were used). 
These then were oven dried at $60^{\circ} \mathrm{C}$ for 4 to 6 hours and crashed into powder using a motor (drying was done so as to accurately calculate the HTL product yields: biocrude oil, solid residue and gas phase). Figure 1 shows a summary of the steps.

The moisture and ash content in the biomass powder was determined by TGA Analysis. TGA analysis was performed in nitrogen on a TG Setaram 92 microbalance. The ramp rate was $10{ }^{\circ} \mathrm{C} \cdot \mathrm{min}^{-1}$ from ambient temperature to $1000^{\circ} \mathrm{C}$. A moisture content of $8.0 \%$ and an ash content of $16.9 \%$ were recorded. The carbon, hydrogen, nitrogen, oxygen and sulphur composition of biomass was also determined and the results presented in Table 1 in the results and discussion section.

\subsubsection{Hydrothermal Liquefaction of Water Hyacinth}

HTL experiments were carried out in a $50 \mathrm{ml}$ stainless steel batch reactor autoclave (CF series) fitted with a pressure gauge and a thermocouple to record temperature (Figure 1(c)). The HTL experiments were done at different reaction conditions of residence time, MNPs to biomass ratios, biomass to water ratios and temperature. The reactor was loaded with a specified amount of water hyacinth biomass and distilled water and inserted in a pre-heated furnace/heating mantle set to a specified temperature for the different reaction conditions (Figure 1(c)). The temperature profile was logged at intervals of 10 seconds using a data logging software. The initial and final pressure was read off directly from the pressure gauge. The effect of MNPs on the biocrude yield and composition was investigated at the following reaction conditions: 1) At temperatures of $280^{\circ} \mathrm{C}, 290^{\circ} \mathrm{C}, 300^{\circ} \mathrm{C}, 310^{\circ} \mathrm{C}, 320^{\circ} \mathrm{C}, 330^{\circ} \mathrm{C}$ and $\left.340^{\circ} \mathrm{C}, 2\right)$ reaction times of 15 , $30,45,60,75$ and 90 minutes, 3) ratios of MNPs to biomass of $0,0.05,0.1,0.2$, $0.3,0.4$ and $0.5 \mathrm{~g} / \mathrm{g}$ and biomass: water ratio of $0.2,0.08,0.06,0.04$ and $0.03 \mathrm{~g} / \mathrm{g}$. After HTL reactions, the reactor was allowed to cool to room temperature and the products separated as illustrated in Figure 2.

The aqueous phase was filtered using a cellulose filter paper, the water was evaporated in a drier and the biocrude oil in the aqueous phase was dissolved in
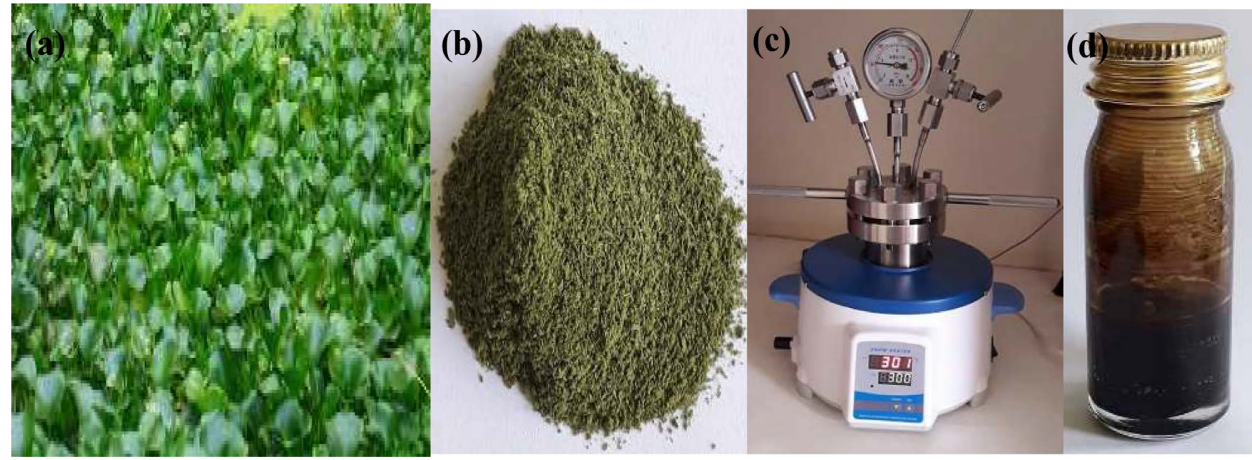

Figure 1. (a) Water hyacinth on the lake, (b) processed water hyacinth powder, (c) the batch HTL reactor used in these experiments and (d) Biocrude oil from the water hyacinth after HTL at $320^{\circ} \mathrm{C}$ for 30 minutes. 


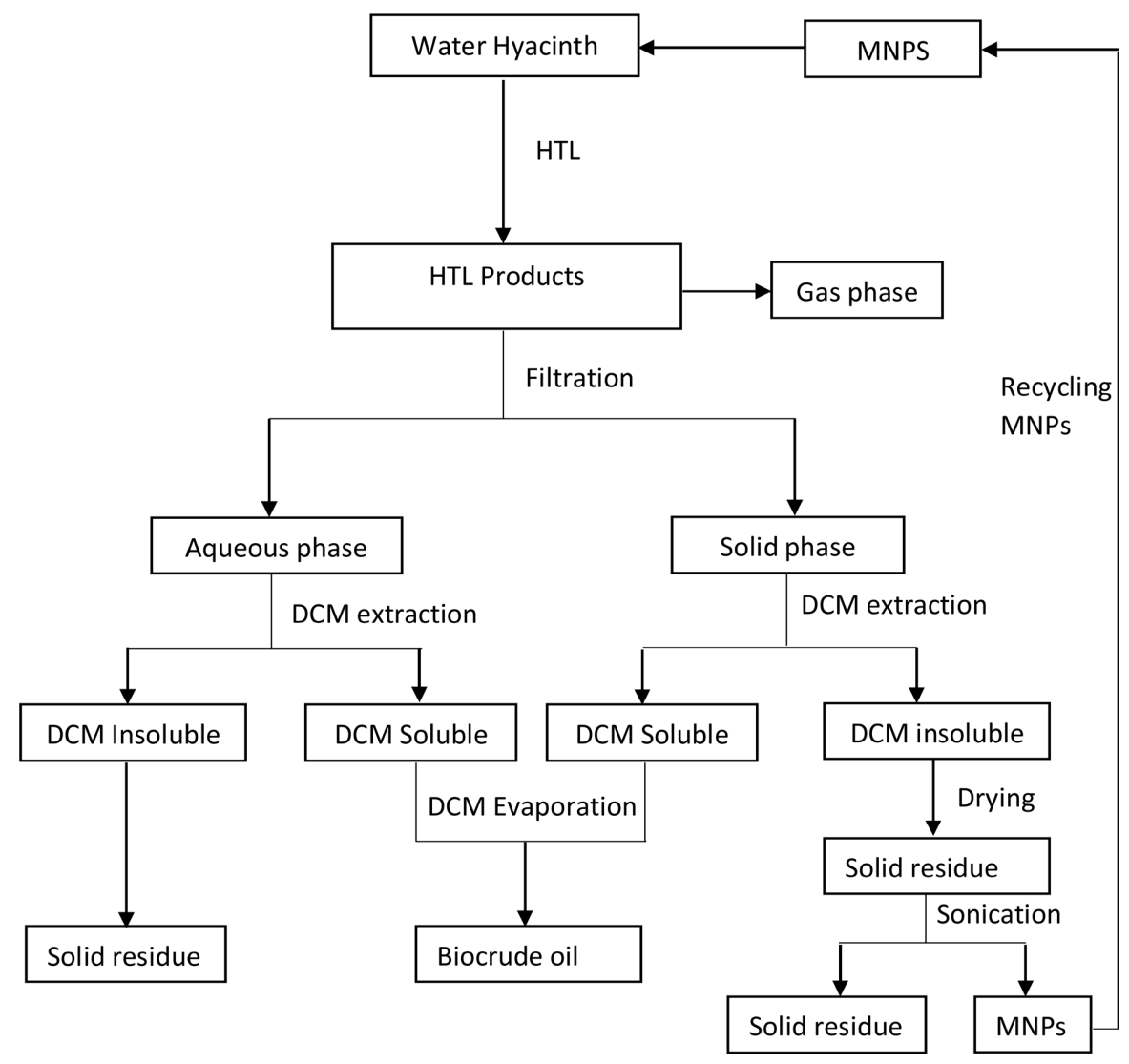

Figure 2. Experimental flow chart for catalytic HTL of water hyacinth using MNPs. MNPs were recycled after HTL for up to 5 cycles.

DCM. After evaporating the DCM phase, the biocrude yield in the aqueous phase (light oils) was added to the biocrude yield in the solid phase (heavy oil) to get the total biocrude yield. The quantity of dissolved solids in the aqueous phase was determined by evaporating the DCM using a rota evaporator and weighing. The DCM insoluble solids in the aqueous phase were also weighted. Bio-crudes were extracted from the solid phase using DCM. The DCM was separated from the bio-crude using a rotary evaporator operated under vacuum conditions at $30^{\circ} \mathrm{C}$ at a rotation speed of $30 \mathrm{rpm}$. The weight of bio-crude was measured by subtracting the weight of the glass vial with bio-crude from the weight of empty glass vial. The weight of solid residue was determined by subtracting the weight of dried filter paper with solids from the weight of empty dried filter paper. The MNPs were deposited in the solid residue and recovered by sonication in de-ionised water (for 30 minutes) to weaken the attachment between biomass and MNPs. All experiments were performed in duplicate and error analysis was done by calculating the standard deviation.

\subsubsection{Recycling of MNPs}

The magnetite nanoparticles were recovered according to our previous method reported in [14]. In this method, the dry solid residue containing MNPs was suspended in de-ionized and deoxygenated water and sonicated for $10-30 \mathrm{mi}-$ 
nutes. The biomass floated to the surface of the water from where it was skimmed off and the MNPs were recovered magnetically. This recovery/cleaning process was repeated at least twice to recover clean and biomass free MNPs. The recovered MNPs were then weighed and recycled for further HTL reactions under similar reaction conditions.

\subsubsection{Biocrude Oil Analysis}

The percentage yield of HTL products (biocrude, solid residue and gas) was calculated using Equation (1). Where MNPs were used the weight of MNPs was subtracted from the solid residue, the yield of biocrude oil and solid residue was calculated on an ash and moisture free basis.

$$
Y_{B C}=\frac{W_{P}}{W_{W H}-W_{A}-W_{M}} \times 100(\%)
$$

where, $Y_{P}$ is the percentage yield of the product, $W_{p}$ is the weight of product (g), $W_{W H}$ is the weight of the water hyacinth fed into the reactor, $W_{A}$ and $W_{M}$ are ash and moisture content of the water hyacinth respectively. The ash content for the water hyacinth varied between $16.8 \%$ to $18.5 \%$ and the moisture content was between $5 \%$ to $8 \%$. The high heating value ( $H H V$ ) of the biocrude oil was calculated using the Dulong's formula [10] [18] see Equation (2).

$$
H H V\left(\mathrm{MJ} \cdot \mathrm{kg}^{-1}\right)=0.3383 C+1.428(H-O / 8)+0.095 S
$$

where: $H H V$ is the high heating value, $C, H, O$ and $S$ are the wt.\% of carbon, hydrogen, oxygen and sulphur present in the product. The energy recovery $(E R)$ of the biocrude oil was calculated according to Equation (3) [15] [19].

$$
E R=\frac{H H V_{P} \times Y_{B C}}{H H V_{F} \times W_{F}} \times 100(\%)
$$

where: $E R$ is the energy recovery, $H H V_{P}$ is high heating value of product, $H H V_{F}$ is high heating value of the feed, $Y_{B C}$ is the yield of biocrude oil and $W_{F}$ is the weight of the feed.

\subsubsection{Analytical Techniques}

UV-Vis analysis of MNPs was done on a UV-Vis Cary series instrument JEM-1200 EX11. Shape, size, and dispersion of the MNPs were analysed using a JEM-1200 EX11 transmission electron microscope (TEM) at an acceleration voltage of 300 Kv. The size distribution of MNPs was determined using image J software. The crystal structure and phase composition of MNPs were characterized on a Bruker D8 Advanced X-ray diffraction (XRD) machine operating at $40 \mathrm{kV}$ and $80 \mathrm{~mA}$ and a scanning rate of $0.02^{\circ} / \mathrm{s}$ in $2 \theta$ range from $20^{\circ}$ to $70^{\circ}$ and wavelength of $1.54056 \AA$. Compounds in the biocrude oil were dissolved in hexane and analysed by a GC-MS analyzer (TQ8040 Shimadzu from UK). Chromatographic conditions were: HP-5 Dimethylpolysiloxane column $(30 \mathrm{~m} \times 0.25 \mathrm{~mm} \times 0.25$ $\mu \mathrm{m}$ ) with $\mathrm{He}$ as the carrier gas and flow rate of $1.77 \mathrm{ml} / \mathrm{min}$. The inlet temperature was $250^{\circ} \mathrm{C}$, the split ratio was -1.0 , and the injection volume was $50 \mathrm{ml}$. Programmed heating: the initial temperature was $80^{\circ} \mathrm{C}$, maintained for $5 \mathrm{~min}$, and 
then increased to $300^{\circ} \mathrm{C}$ at a rate of $4^{\circ} \mathrm{C} / \mathrm{min}$ and maintained for an additional 7 min. MS conditions were as follows: EI source, ion source temperature of $230^{\circ} \mathrm{C}$, multiplier voltage of $300 \mathrm{~V}$, interface temperature of $250^{\circ} \mathrm{C}$ and solvent delay time of $3.5 \mathrm{~min}$. Samples were analysed for elemental composition for nitrogen, carbon, hydrogen and sulphur using a Thermo model EA1110 elemental analyser, running Xperience EA software, single tube configured for simultaneous $\mathrm{CHN}$ or CHNS analysis using a Porapak QS 2 metre separation column. References and samples were weighed to 6 decimal places using a Mettler UMX5 microbalance. Samples were analysed for elemental composition for oxygen using a Thermo model EA1110 elemental analyser, running Xperience EA software, single tube configured for oxygen analysis using a Molecular Sieve 3A separation column. References and samples were weighed to 6 decimal places using a Mettler UMX5 microbalance.

\section{Results and Discussion}

\subsection{Characterisation of MNPs}

The MNPs used in the catalytic HTL of the water hyacinth were characterised by TEM, XRD and UV-Vis. TEM images (Figure 3) show the hexagonal morphology of the MNPs. The nanoparticles were crystalline and mono dispersed and their size ranges between $11-19 \mathrm{~nm}$ with an average particle size of $15 \mathrm{~nm}$. The particle size distribution was measured using image J software and it can be seen from Figure 4 that most of the nanoparticles were in the size range of $11 \mathrm{~nm}$, followed by $13 \mathrm{~nm}$. From their hexagonal morphology, it can be confirmed that magnetite nanoparticles were successfully synthesised.

From XRD characterisation (Figure 5), it was observed that reflections which correspond to magnetite nanoparticles were found at $2 \theta=30.437^{\circ}, 35.715^{\circ}$, $43.393^{\circ}, 53.950^{\circ}$ and $57.309^{\circ}$ corresponding to the (220), (311), (400), (422), and (511) crystal planes of pure magnetite. These peaks match well with the reported peaks in literature for magnetite [20]. Formation of magnetite nanoparticles was also characterised by UV-Vis (Figure 6). From the UV-Vis spectrum, hydrolysis
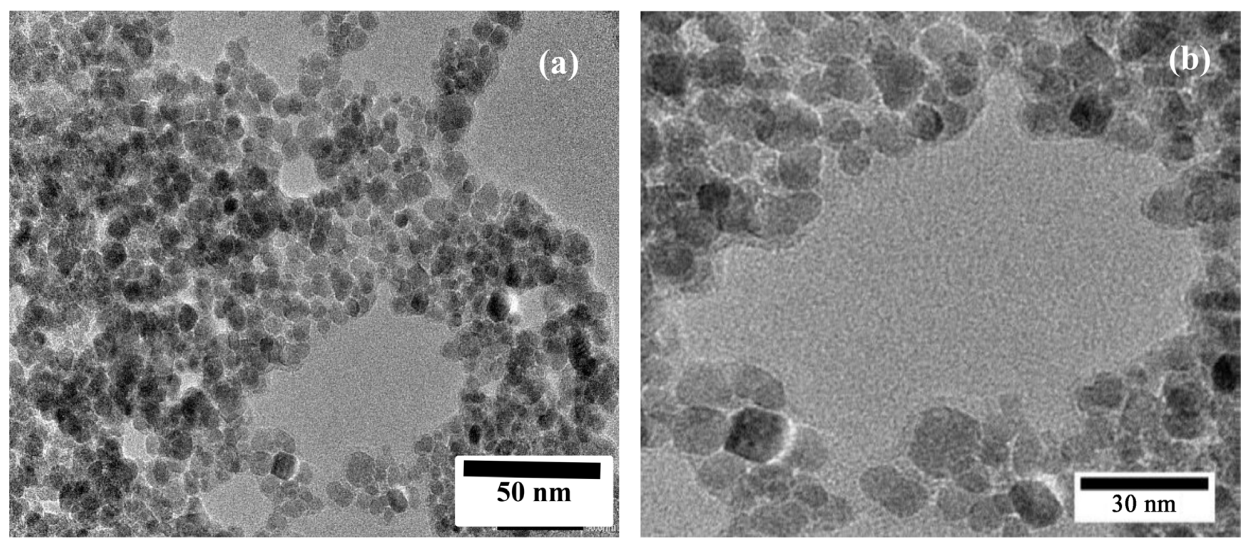

Figure 3. TEM images of iron oxide magnetite nanoparticles synthesised by the co-precipitation method (a) at a magnification of $50 \mathrm{~nm}$ and (b) at a magnification of $30 \mathrm{~nm}$. 


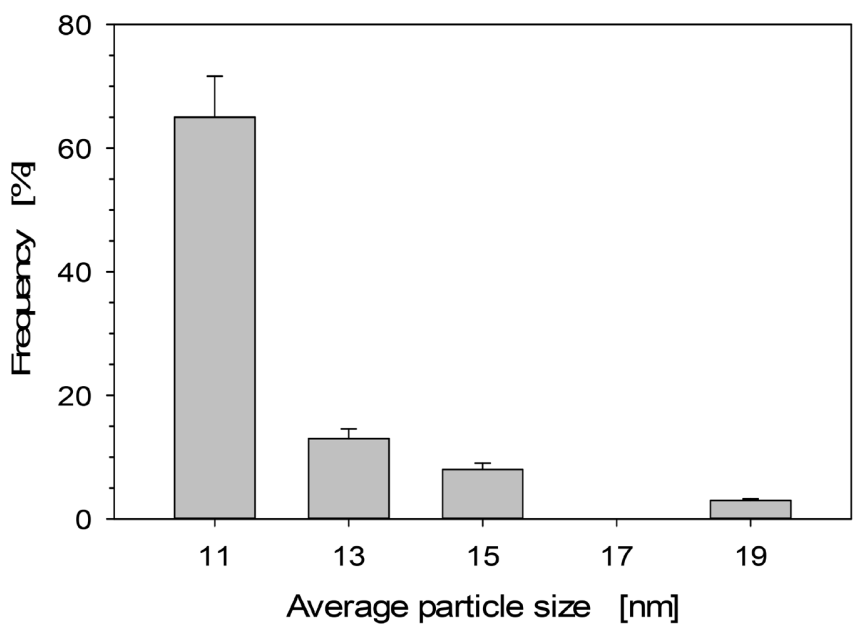

Figure 4. Particle size distribution of magnetite (MNPs) synthesised by the co-precipitation [14].

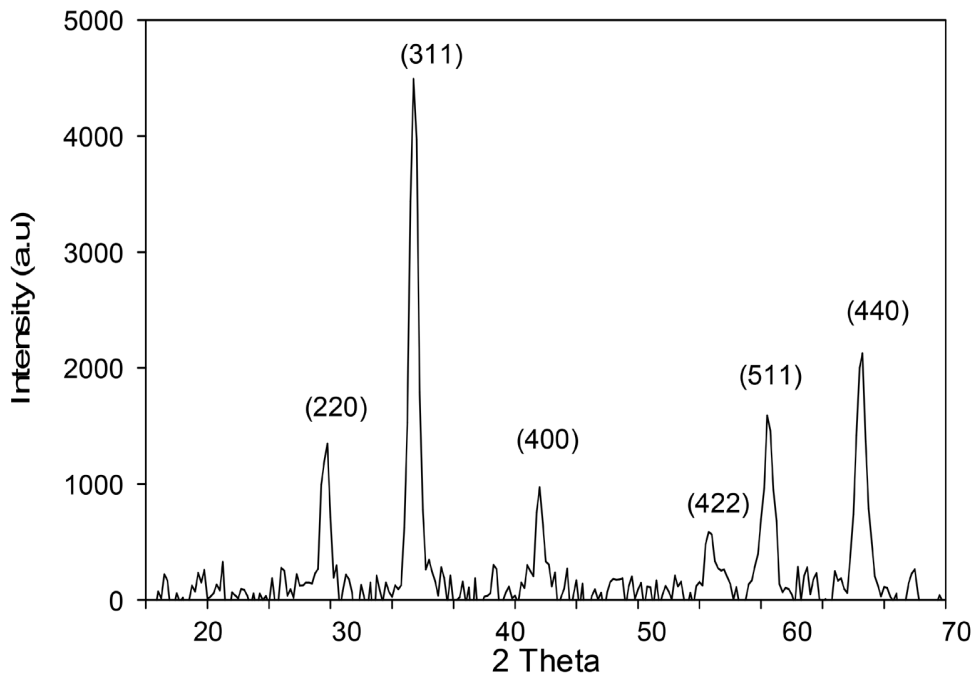

Figure 5. XRD spectra of magnetite nanoparticles confirming the standard magnetite peaks [14].

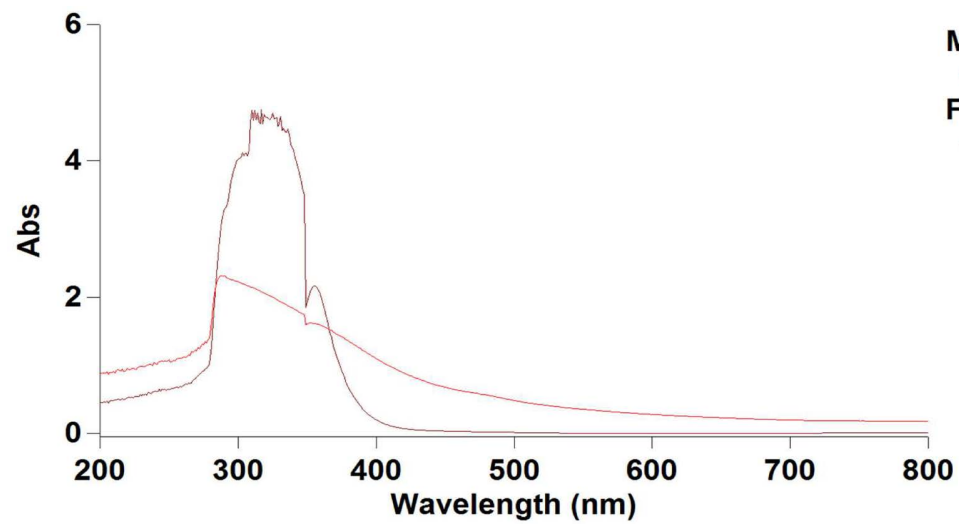

\section{Magnetite}

Fe II and III

Figure 6. UV-Vis spectrum for iron oxide magnetic nanoparticles (magnetite) and a mixture of iron (ii) and iron (iii) oxide (ratio 1:2) solution from which magnetite nanoparticles were formed [14]. 
of iron ions in presence of ammonium hydroxide resulted into removal of metal-ion complex from solution leading to the disappearance of the peak at 300 $\mathrm{nm}$ (corresponding to iron (ii) and iron (iii) oxide solution) and to formation of a second broad featureless absorption tail (corresponding to magnetite nanoparticles) which according to [21] is due to formation of magnetite and is as a result of transition in band gap of semiconductor materials. The new peak corresponding to formation of magnetite further confirms that MNPs were successfully synthesised by the co-precipitation process.

\subsection{Effect of Process Conditions and MNPs on Biocrude Yield and Composition}

The process conditions investigated included: reaction time, ratio of MNPs to biomass, ratio of biomass to water and temperatures.

\subsubsection{Effect of Reaction Time and MNPs}

To investigate the effect of reaction time, hydrothermal liquefaction of water hyacinth was done in presence and absence of MNPs at $320^{\circ} \mathrm{C}$, biomass to water ratio of 1:18 and at varying liquefaction times $(15,30,45,60,75$ and 90 minutes) as shown in Figure 7 and Figure 8. For HTL in absence of MNPs, the biocrude yield increased steadily with increase in reaction time from $33 \mathrm{wt} \%$ after $15 \mathrm{mi}$ nutes to a peak of $53 \mathrm{wt} \%$ after 60 minutes. Further increase in reaction time beyond 60 minutes led to a gradual reduction in the biocrude yield up to the lowest value of 44 wt\% after 90 minutes (Figure 7 and Figure 8(a)). When HTL was done in presence of MNPs, a similar trend in biocrude yield was observed but the difference was in the higher biocrude yields registered when MNPs were used (Figure 8(a)). HTL in presence of MNPs led to a gradual increase in biocrude yield from $40 \mathrm{wt} \%$ to a peak of $58 \mathrm{wt} \%$ and then reduced gradually to 53 and $45 \mathrm{wt} \%$ after 60 and 90 minutes of reaction respectively. The high biocrude yield in presence of MNPs shows that they played a catalytic role by selectively favoring

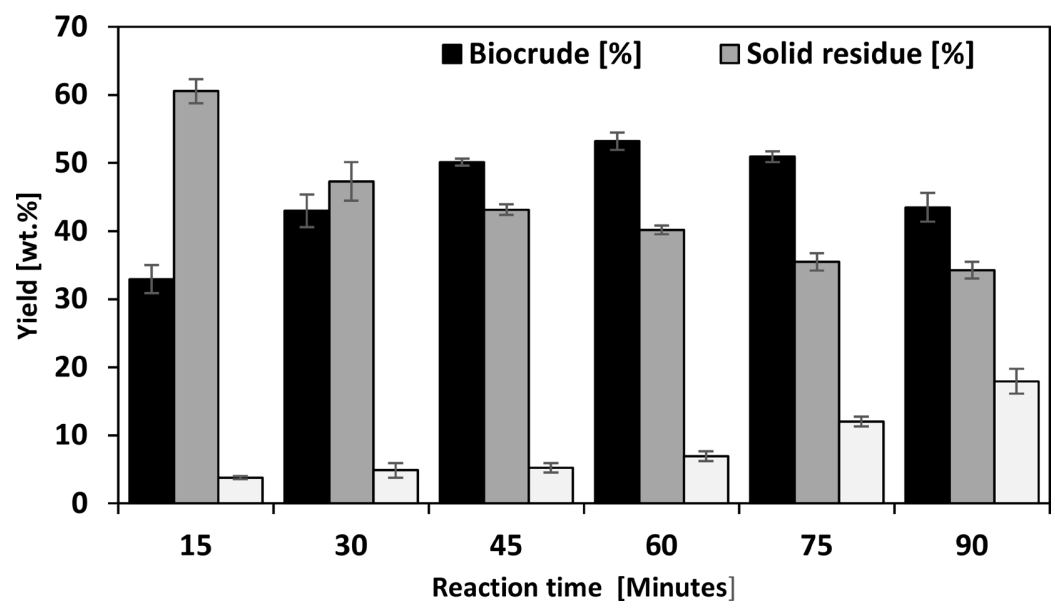

Figure 7. Effect of reaction time on HTL products (biocrude oil, solid residue and gas yields) in absence of MNPs at a temperature of $320^{\circ} \mathrm{C}$ and biomass to water ratio of 1 to $18(0.06 \mathrm{~g} / \mathrm{g})$. 

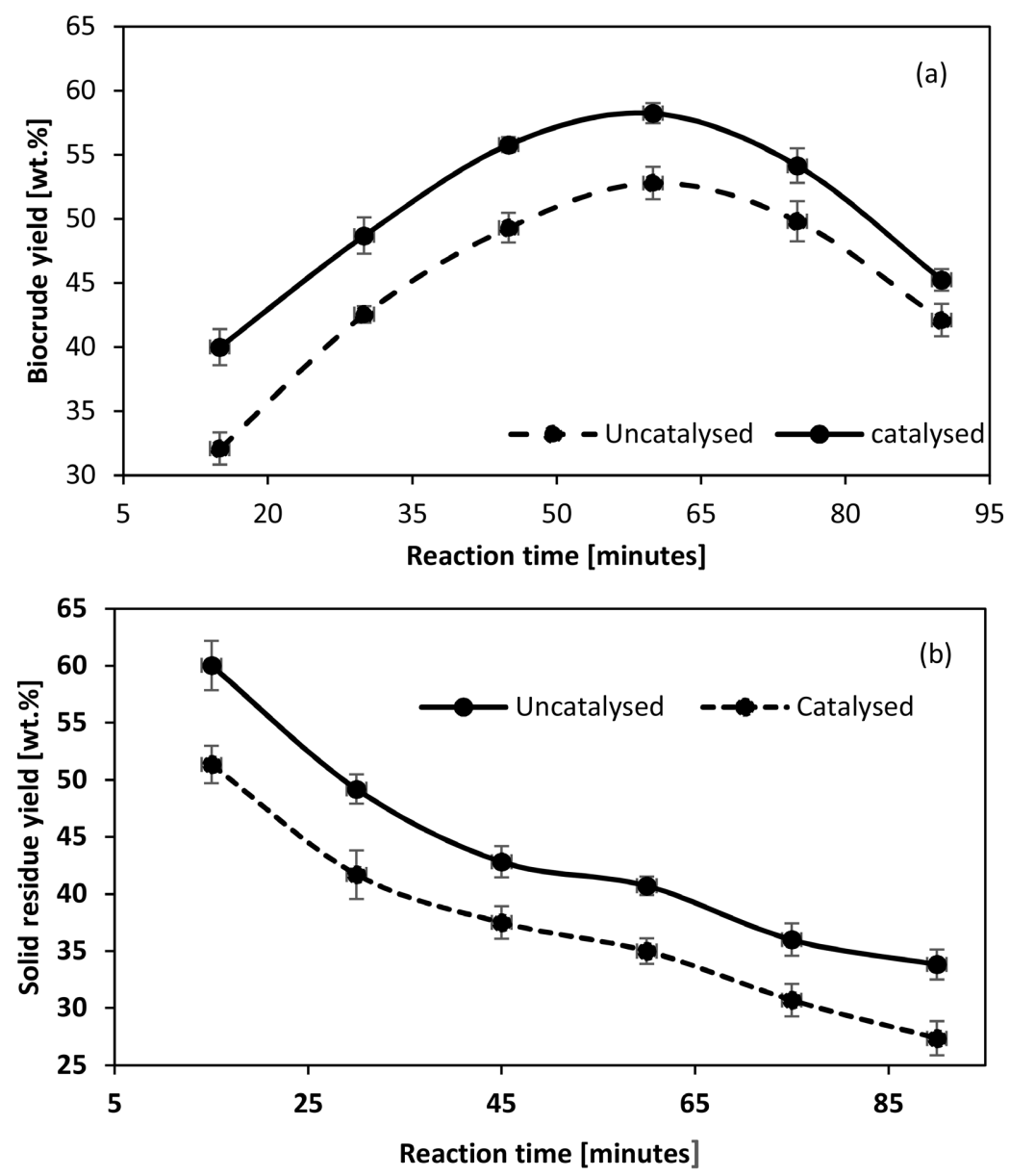

Figure 8. Effect of MNPs on biocrude oil and solid residue yield at different reaction times for HTL in presence of MNPs (catalyzed) and HTL in absence of MNPs (uncatalyzed). The reaction temperature was maintained at $320^{\circ} \mathrm{C}$, water to biomass ratio at 1 to 18 and at a ratio of MNPs to water hyacinth of 1:5 (0.2 g/g). (a) Biocrude yield and (b) solid residue yield.

reactions that led to the conversion of biomass to biocrude oil. A similar catalytic effect of MNPs in HTL of a different biomass feedstock (algae) was observed by [10] [15].

Studies on HTL of oak wood revealed that MNPs owe their catalytic activity on the degradation of cellulose and lignin, promoting the dehydration reactions which are partly responsible for the increase in the biocrude yield [22].

The catalytic effect of MNPs can further be evidenced by a lower solid residue yield in liquefactions involving MNPs and a higher solid residue yield in liquefactions without MNPs (Figure 8(b)). This is an indication that MNPs are favoring the conversion of solid residue to biocrude by favoring reactions that lead to biocrude production to those that lead to solid residue production. Culminating in a reduced solid residue yield and a higher biocrude yield for HTL in presence of MNPs.

The increase in biocrude yield with increasing reaction time in the first 60 minutes can be attributed to the polymerization of the small reactive compounds 
to form biocrude oil [23] [24]. These small reactive compounds are formed through the hydrolysis of biomass at the initial stage of the HTL process. Therefore, in the first 60 minutes, the polymerization reactions to form biocrude oil are more favored. The reduction in biocrude yield at higher reaction times is potentially due to the breakdown of components in the biocrude oil into the gaseous phase. This is evidenced by the increase in the gas yields at higher reaction times (Figure 7). This observation is also confirmed by the decrease in biocrude viscosity with increase in reaction time [25]. The reduction in biocrude yield at higher reaction times may also be attributed to the decomposition of the intermediate HTL products capable of forming biocrude oil into the gas and the char phase through condensation, crystallization and depolymerization reactions. It can therefore be concluded that increase in biocrude yield in the first 60 minutes was due to increased polymerization reaction while a reduction in biocrude yield beyond 60 minutes was due to increased decomposition of biocrude oil to the gas phase through condensation, crystallization and depolymerization reactions among others. It can be seen that in the first 60 minutes of reaction, the role of MNPs was to favor the reactions that led to the formation of biocrude oil leading to an increase in biocrude yield. In addition, beyond the peak reaction time, the MNPs favored reactions that led to reduction in biocrude yield and solid residue and those that favored increase in gas yield.

On the other hand, increase in reaction time led to a gradual reduction in the solid residue yield both in presence and absence of MNPs though the reduction was highest in presence of MNPs (Figure 7 and Figure 8(b)). In absence of MNPs, the solid residue yield reduced gradually from $60 \mathrm{wt} \%$ to the lowest value of $34 \mathrm{wt} \%$ after 15 and 90 minutes respectively. In presence of MNPs, it decreased gradually from $51 \mathrm{wt} \%$ to $27 \mathrm{wt} \%$ after 15 and 90 minutes of reaction respectively. The reduction in solid residue yield is attributed to the decomposition of the solid phase into the gas phase as explained earlier. This is evidenced by the increase in the gas yield at higher reaction times (Figure 7). A similar trend in gas yield increment and solid yield reductions at higher reaction times was observed by Yan et al. during the HTL of Sugar cane bagasse [26], though the biomass feedstocks are different, the HTL reaction mechanisms are largely the same. The steady increase in gas yield is attributed to the increasing decomposition of the solid residue and biocrude oil into the gaseous phase at higher reaction times. This was due to the increase in decomposition, hydrolysis and depolymerisation reactions. This is evidenced by the reduction in the biocrude and solid residue yield at higher reaction times (Figure 7).

\subsubsection{Effect of MNPs: Biomass Ratio}

The effect of ratio of MNPs to biomass on biocrude yield was also investigated (Figure 9).

All other reaction conditions were kept constant. The reaction time of $60 \mathrm{mi}-$ nutes, temperature of $320^{\circ} \mathrm{C}$ and biomass to water loading of 1:18 giving a water content of $94.7 \%$ which is directly in the range for HTL. The yield of biocrude 


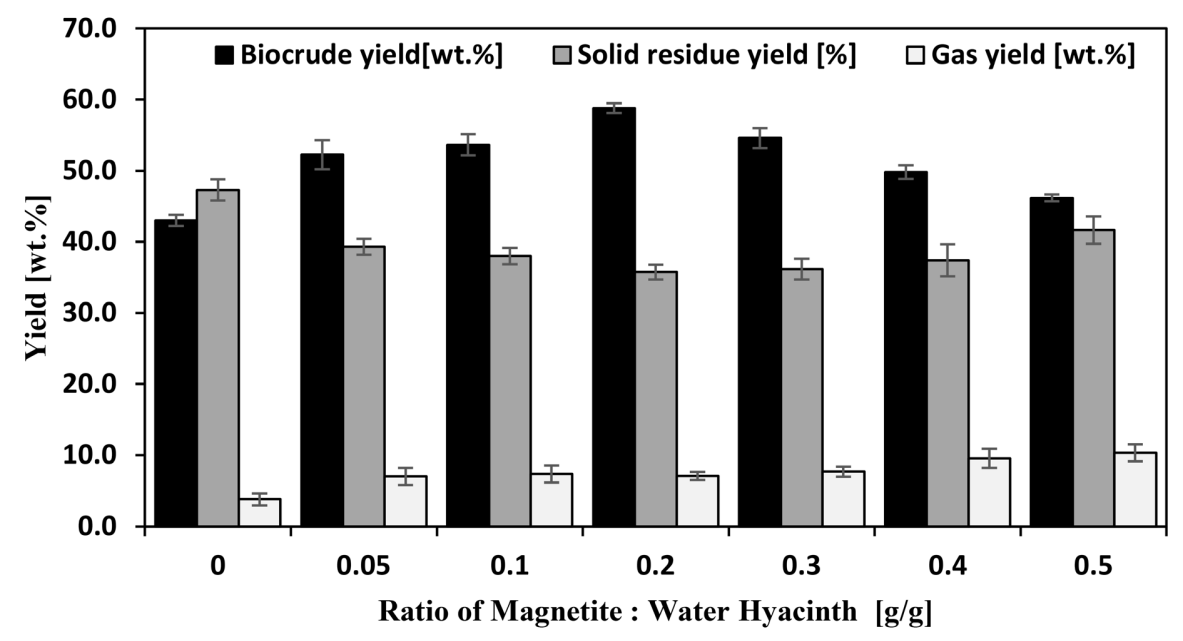

Figure 9. Yield of biocrude oil, solid residue and gas after HTL of water Hyacinth at different mass ratio of MNPs to biomass done at $320^{\circ} \mathrm{C}$ for 60 minutes. The experiments were done in duplicate and the error calculated based on standard deviation.

oil increased steadily from $43 \mathrm{wt} \%$ at a ratio of MNPs to biomass of $0 \mathrm{~g} / \mathrm{g}$ (in absence of MNPs) to the highest yield of $58.8 \mathrm{wt} \%$ at a ratio of MNPs to biomass of $0.2 \mathrm{~g} / \mathrm{g}$. Further increase in mass ratio of MNPs to biomass led to a gradual reduction in biocrude yield up to the lowest yield of $46.2 \mathrm{wt} \%$ at a mass ratio of MNPs to biomass of $0.5 \mathrm{~g} / \mathrm{g}$.

Similar trends in oil yield with mass ratio of catalyst to biomass have been observed in a number of studies for different feedstock such as microalgae and coal liquefaction [10] [15] [27]. These studies found that optimum yields were obtained at low catalyst mass ratios. This is because at low MNPs (catalyst) ratios there is an even distribution of MNPs on the surface of the biomass resulting in maximum exposure of the catalyst active sites for the biomass conversion reactions leading to increased biocrude yield [14]. On the other hand, the reduction in biocrude yield at higher ratios of MNPs to biomass is attributed to increased particle aggregation at higher concentrations of MNPs [14]. This led to loss of catalyst and a reduced exposure of biomass to the catalyst active sites leading to a reduction in catalytic activity hence the gradual reduction in biocrude yield. Therefore, the biocrude yield can be enhanced by an optimum amount of catalyst in HTL reactions. The steady increase in biocrude yield from the initial yield of $43 \mathrm{wt} \%$ to the peak yield of $58.8 \mathrm{wt} \%$ corresponds to the steady reduction in solid residue yield in the same region (Figure 9). This shows that MNPs played a catalytic role in favouring the conversion of biomass to biocrude oil over the conversion of biomass to solid residue. As a result, there was a reduction in solid residue yield and an increase in biocrude yield. In summary, to achieve higher biocrude oil yields, an optimum mass ratio of MNPs to water hyacinth biomass is needed. Higher ratios of MNPs to biomass will result in a reduced biocrude yield and is not economically viable since a large amount of MNPs is needed. Under these experimental conditions, the optimum mass ratio of MNPs to biomass is $0.2 \mathrm{~g} / \mathrm{g}$. 


\subsubsection{Effect of Temperature}

The effect of temperature on biocrude yield was investigated in presence and absence of MNPs (Figure 10). The reaction time was maintained at 30 minutes, the biomass to water ratio at $0.06 \mathrm{~g} / \mathrm{g}$ and the ratio of MNPs to biomass was maintained at $0.2 \mathrm{~g} / \mathrm{g}$. The temperature was varied between $280^{\circ} \mathrm{C}$ to $340^{\circ} \mathrm{C}$. The biocrude yield increased gradually from $37.4 \mathrm{wt} \%$ at $280^{\circ} \mathrm{C}$ to a peak of $43.2 \mathrm{wt} \%$ at $320^{\circ} \mathrm{C}$. Increase in temperature beyond $320^{\circ} \mathrm{C}$ resulted in a gradual reduction in biocrude yield up to its lowest yield of $35.2 \mathrm{wt} \%$ at $340^{\circ} \mathrm{C}$. The initial increase in biocrude yield with temperature is attributed to an increased decomposition and depolymerization of biomass into smaller compounds [28]. The reduction in biocrude yield beyond the peak temperature is attributed to the Boudouard reactions and the secondary reactions which are activated at higher temperatures [26] [29]. The increase in gas yields at higher temperatures as seen in Figure 10(a)
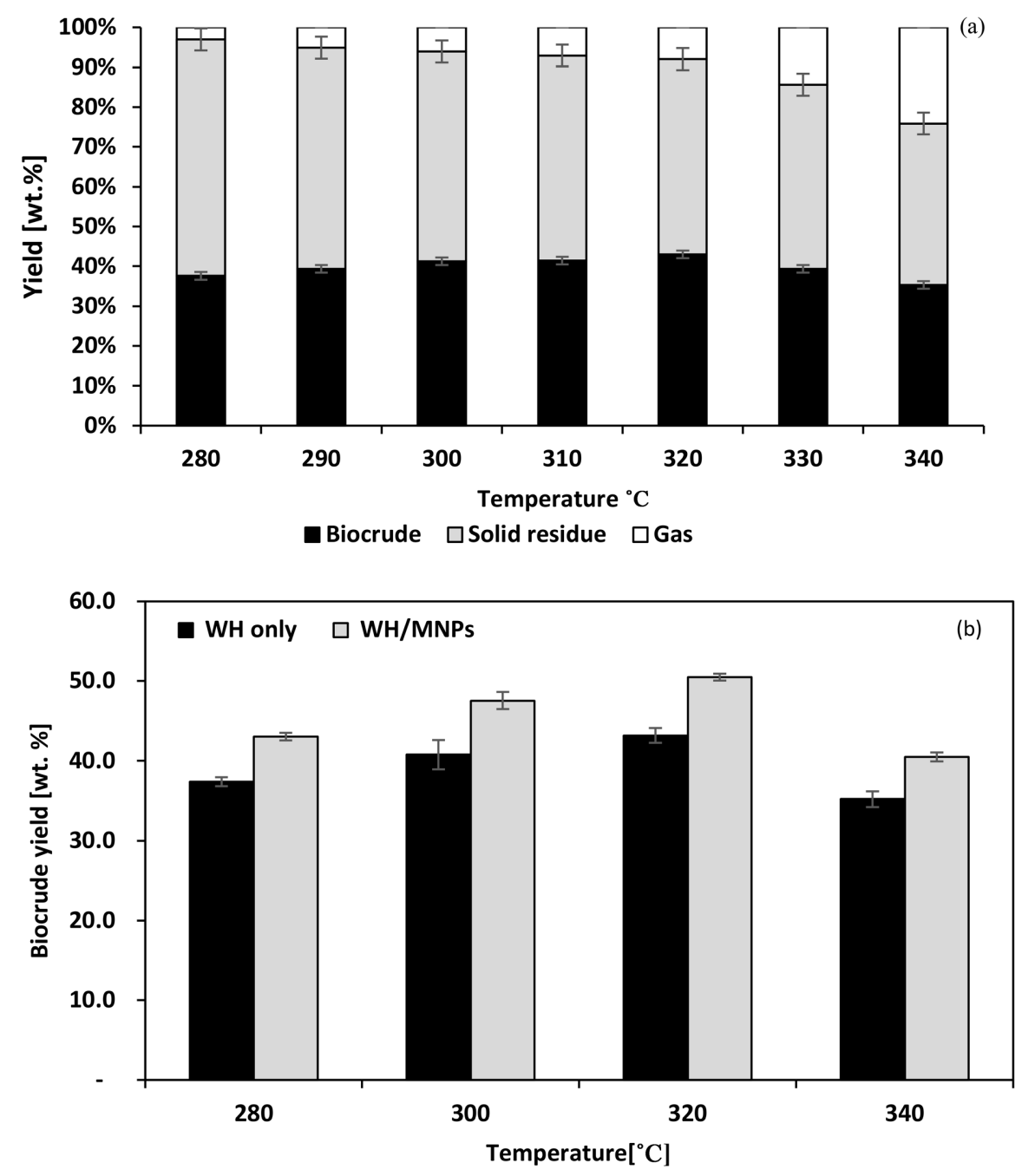

Figure 10. Effect of temperature on the biocrude yield from water hyacinth (WH) HTL: (a) yield of biocrude, solid residue and gas at different temperatures in absence of MNPs, (b) yield of biocrude oil in presence and absence of MNPs. The reaction time was $30 \mathrm{mi}-$ nutes and the reaction was done in duplicate and error calculated from standard deviation. 
confirms the activation of secondary and Boudouard reactions leading to biocrude evaporation into the gas phase. The reduction in biocrude yield at higher temperatures could also be due to the re-arrangement of the smaller compounds in the biocrude oil to form new compounds through cyclisation, condensation and polymerization reactions [28]. Some of these reactions may lead to a slight increase in the solid residue yield as well [26]. These results show that some reactions are more pronounced at certain reaction conditions. The gradual reduction in solid residue yield also confirms that solid residue was decomposed to biocrude oil at lower temperatures and to gas at higher temperatures. A similar trend in biocrude yield was observed when HTL was done in presence of MNPs (Figure 10(b)). The only difference was that the yield of biocrude oil was higher when MNPs were used in the liquefaction process. HTL in presence of MNPs led to an increment in the biocrude yield by $5.7 \mathrm{wt} \%$ at $280^{\circ} \mathrm{C}, 6.8 \mathrm{wt} \%$ at $300^{\circ} \mathrm{C}, 7.3$ wt $\%$ at $320^{\circ} \mathrm{C}$ and $5.3 \mathrm{wt} \%$ at $340^{\circ} \mathrm{C}$. In summary, these results show that MNPs played a catalytic role favoring reaction that led to increase in biocrude oil formation. In addition, HTL of biomass at higher temperatures result in a reduction in biocrude oil yield. Under these reaction conditions, the optimum temperature is $320^{\circ} \mathrm{C}$

\subsubsection{Effect of Biomass: Water Ratio}

The effect of biomass to water ratios on biocrude oil yield was also investigated. The biomass was maintained at $1 \mathrm{~g}$ and the amount of water was increased from $6,12,18,24$ and to $30 \mathrm{~g}$. The temperature was maintained at $320^{\circ} \mathrm{C}$ and the reaction time was kept at 30 minutes (Figure 11). The liquefaction was done in absence of MNPs, the aim was to determine the optimum biomass to water loading and the effect of biomass to water ratio on biocrude yield.

The biocrude yield increased steadily with increase in the mass ratio of biomass to water. It reached its peak ( $46 \mathrm{wt} \%$ ) at a mass ratio of biomass to water of $0.06 \mathrm{~g} / \mathrm{g}$ then reduced slightly with further increase in the biomass to water ratio, reaching its lowest value of $39 \mathrm{wt} \%$ at a ratio of $0.03 \mathrm{~g} / \mathrm{g}(1: 30)$ as seen in Figure 11.

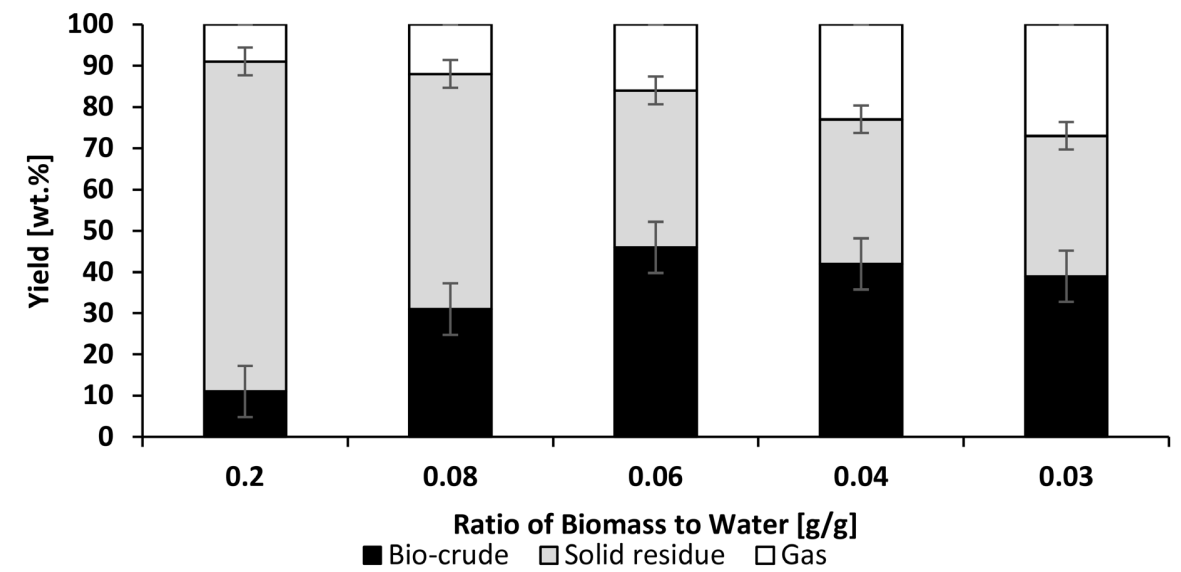

Figure 11. Percentage yield of biocrude, solid residue and gas at different mass ratios of water hyacinth biomass to water after 30 minutes of $\mathrm{HTL}$ at $320^{\circ} \mathrm{C}$. 
The gradual increase in biocrude yield with reducing biomass to water ratio is possibly due to a steady increase in the effect of the $\mathrm{H}^{+}$and $\mathrm{OH}^{-}$ions from water since there concentration increases with the increasing mass of water. It is well known that during the HTL process, hot compressed water is under subcritical state and under such conditions, its properties are different from water at standard conditions [30]. These properties include: 1) weakening and reduction in number of hydrogen bonds, 2) there are more ions in solution due to the increase in ionic product of water $\left(10-12\right.$ compared to $10-14$ at $\left.25^{\circ} \mathrm{C}\right)$ leading to increased concentration of $\mathrm{H}+$ and $\mathrm{OH}-$ ions [30], there is promotion of reactions that are catalysed by acids and bases for example hydrolysis reactions and 3 ) there is an increase in the solubility of hydrophobic organic compounds due to a reduced permittivity of water (from $78 \mathrm{~F} \cdot \mathrm{m}^{-1}$ at $25^{\circ} \mathrm{C}$ and 1 bar to 14.07 $\mathrm{F} \cdot \mathrm{m}^{-1}$ at $350^{\circ} \mathrm{C}$ and 200 bar) [31].

Therefore, increasing the amount of water increases the concentration of $\mathrm{H}^{+}$ and $\mathrm{OH}^{-}$ions in the reaction medium and hence their reactive effect in converting biomass to biocrude oil increases. As a result, there was an increase in the biocrude oil yield as observed in Figure 11.

However, further increase in the mass of biomass to water ratio had no significant effect on increasing the biocrude yield. This is possibly due to presence of excess $\mathrm{H}^{+}$and $\mathrm{OH}^{-}$ions in the reaction mixture resulting in a reduction in their catalytic activity hence a slight reduction in the biomass conversion to biocrude oil. The solid residue yield decreased steadily with increasing amount of water i.e. The very high solid residue yield initially at $0.2 \mathrm{~g} / \mathrm{g}$ was potentially due to a very low concentration of $\mathrm{H}^{+}$and $\mathrm{OH}^{-}$ions reducing their catalytic role in converting biomass to biocrude oil. As a result, much of the biomass was not converted to biocrude resulting in a very low biocrude yield (Figure 11).

Another possible reason for the high solid residue yield and low biocrude yields initially is that at high biomass to water ratios, there is a decreased solvation for biomass components due to limited amount of water [32]. The decrease in solvation limits the reactions that convert biomass to biocrude oil resulting in a high solid residue. A similar observation was reported by Boocock et al. when liquefying wood. They reported that a low water to wood ratio affected the chemical role of water in breaking down wood [33]. It can be concluded that an optimum biomass to water ratio is needed in the HTL of biomass. Under these experimental conditions, the optimum ratio of biomass to water was 1:18 (0.06 $\mathrm{g} / \mathrm{g}$ ). The steady increase in the gas yield with an increase in the amount of water was potentially due to the increase in evaporation brought about by the increased water content. The other possibility is that, higher solvent results in increased solvolysis reactions which promote the splitting of chemical bonds of intermediates to form definite products [28].

\subsubsection{Analysis of Biocrude Oil Composition}

To analyze the composition or quality of biocrude oils after HTL in presence and absence of MNPs, elemental and GC-MS analysis were carried out on the bio- 
crude oil produced and the findings were presented in the sections below.

\section{1) Elemental Analysis of biocrude oil}

The C, H, N, O and S elemental analysis of biocrude oil was done at different reaction times in presence and absence of MNPs (Table 1 and Figure 12). The aim was to determine the effect of reaction time and MNPs on biocrude composition, High heating value (HHV) and energy recovery (ER). The carbon yield in the biocrude oil was higher than that in the biomass feedstock and HTL in presence of MNPs presented higher yields of carbon than HTL in absence of MNPs (Table 1 and Figure 12(a)). For HTL in presence of MNPs, the carbon content increased from $35.1 \mathrm{wt} \%$ in the biomass feedstock to $63.5 \mathrm{wt} \%$ after 15 minutes of HTL. Further increase in reaction time resulted in a gradual increase in carbon to a peak of $72.8 \mathrm{wt} \%$ after 60 minutes of HTL. Beyond 60 minutes there was a gradual reduction in carbon yield with time as seen in Figure 12(a).

For HTL in absence of MNPs, the carbon content increased gradually from $35.1 \mathrm{wt} \%$ in biomass feedstock to $60.7 \mathrm{wt} \%$ after 15 minutes of HTL. Further increase in reaction time led to a gradual increase in carbon up to a peak of 68.6 wt $\%$ after 60 minutes, then a gradual reduction beyond 60 minutes. The low carbon yields at shorter reaction times are possibly due to a limited reaction time for the conversion of biomass to biocrude. A reduction in carbon yield beyond the optimum reaction time was possibly due to loss of carbon into the gas phase in form of $\mathrm{CO}_{2}$ due to excess heating. From these results, it is evident that the

Table 1. Elemental composition, HHV and ER of Biocrude produced from HTL of water hyacinth biomass in presence and absence of iron oxide MNPs at $320^{\circ} \mathrm{C}$ at different reaction times.

\begin{tabular}{ccccccccccc}
\hline HTL Time (min) & $\begin{array}{c}\mathrm{C} \\
(\mathrm{wt} \%)\end{array}$ & $\begin{array}{c}\mathrm{H} \\
(\mathrm{wt} \%)\end{array}$ & $\begin{array}{c}\mathrm{N} \\
(\mathrm{wt} \%)\end{array}$ & $\begin{array}{c}\mathrm{O} \\
(\mathrm{wt} \%)\end{array}$ & $\begin{array}{c}\mathrm{S} \\
(\mathrm{wt} \%)\end{array}$ & $\begin{array}{c}\mathrm{N} / \mathrm{C}^{*} \\
-\end{array}$ & $\begin{array}{c}\mathrm{H} / \mathrm{C}^{*} \\
\text { O } / \mathrm{C}^{*}\end{array}$ & $\begin{array}{c}\mathrm{HHV} \\
(\mathrm{M} / \mathrm{kg})\end{array}$ & $\begin{array}{c}\mathrm{ER} \\
(\%)\end{array}$ \\
\hline Biomass & $35.1 \pm 0.06$ & $6.1 \pm 0.00$ & $5.4 \pm 0.06$ & $52.1 \pm 0.03$ & $0.60 \pm 0.01$ & 0.11 & 2.09 & 6.41 & $11.3 \pm 0.2$ & 0.0 \\
15 & $60.7 \pm 0.09$ & $7.6 \pm 0.08$ & $4.5 \pm 0.03$ & $27.3 \pm 0.14$ & $0.58 \pm 0.02$ & 0.06 & 1.50 & 2.69 & $26.6 \pm 0.16$ & $30.2 \pm 0.03$ \\
30 & $62.7 \pm 0.05$ & $7.9 \pm 0.04$ & $3.7 \pm 0.01$ & $12.5 \pm 0.01$ & $0.54 \pm 0.00$ & 0.05 & 1.51 & 1.19 & $30.3 \pm 0.04$ & $45.7 \pm 0.05$ \\
45 & $65.4 \pm 0.04$ & $8.2 \pm 0.07$ & $3.2 \pm 0.1$ & $10.3 \pm 0.13$ & $0.51 \pm 0.03$ & 0.04 & 1.50 & 0.94 & $32.0 \pm 0.05$ & $55.9 \pm 0.03$ \\
60 & $68.6 \pm 0.12$ & $8.1 \pm 0.06$ & $2.8 \pm 0.03$ & $7.4 \pm 0.14$ & $0.45 \pm 0.00$ & 0.03 & 1.42 & 0.69 & $33.5 \pm 0.16$ & $62.6 \pm 0.06$ \\
85 & $67.5 \pm 0.03$ & $7.9 \pm 0.04$ & $2.5 \pm 0.01$ & $7.0 \pm 0.21$ & $0.40 \pm 0.01$ & 0.03 & 1.40 & 0.66 & $32.9 \pm 0.01$ & $58.0 \pm 0.07$ \\
105 & $65.7 \pm 0.03$ & $7.7 \pm 0.05$ & $2.0 \pm 0.01$ & $6.5 \pm 0.14$ & $0.35 \pm 0.01$ & 0.03 & 1.41 & 0.63 & $32.1 \pm 0.03$ & $47.8 \pm 0.01$ \\
With MNPs & & & & & & & & & & \\
15 & $63.5 \pm 0.13$ & $7.9 \pm 0.02$ & $3.7 \pm 0.01$ & $20.6 \pm 0.16$ & $0.5 \pm 0.03$ & 0.05 & 1.49 & 1.96 & $29.1 \pm 0.05$ & $41.3 \pm 0.07$ \\
30 & $65.3 \pm 0.14$ & $8.3 \pm 0.01$ & $3.1 \pm 0.11$ & $10.2 \pm 0.04$ & $0.42 \pm 0.03$ & 0.04 & 1.53 & 0.92 & $32.2 \pm 0.06$ & $55.4 \pm 0.03$ \\
45 & $68.5 \pm 0.06$ & $8.5 \pm 0.01$ & $2.4 \pm 0.01$ & $8.4 \pm 0.07$ & $0.34 \pm 0.01$ & 0.03 & 1.49 & 0.74 & $33.8 \pm 0.04$ & $66.9 \pm 0.06$ \\
60 & $72.8 \pm 0.02$ & $8.4 \pm 0.06$ & $2.1 \pm 0.01$ & $6.5 \pm 0.00$ & $0.31 \pm 0.00$ & 0.02 & 1.38 & 0.58 & $35.5 \pm 0.01$ & $73.2 \pm 0.13$ \\
85 & $71.5 \pm 0.16$ & $7.9 \pm 0.03$ & $1.8 \pm 0.00$ & $6.1 \pm 0.01$ & $0.25 \pm 0.00$ & 0.02 & 1.33 & 0.58 & $34.4 \pm 0.1$ & $65.9 \pm 0.03$ \\
105 & $69.4 \pm 0.17$ & $7.5 \pm 0.16$ & $1.5 \pm 0.18$ & $5.5 \pm 0.17$ & $0.20 \pm 0.02$ & 0.02 & 1.30 & 0.55 & $33.2 \pm 0.02$ & $53.2 \pm 0.04$ \\
\hline
\end{tabular}

${ }^{\star}$ Atomic ratios. 
optimum yield of carbon was obtained after 60 minutes of HTL under the specified reaction conditions. It is also clear that HTL in presence of MNPs resulted in higher carbon yields. This shows that MNPs played a catalytic role by favoring reactions that led to an increase in the carbon content of biocrude oil. The
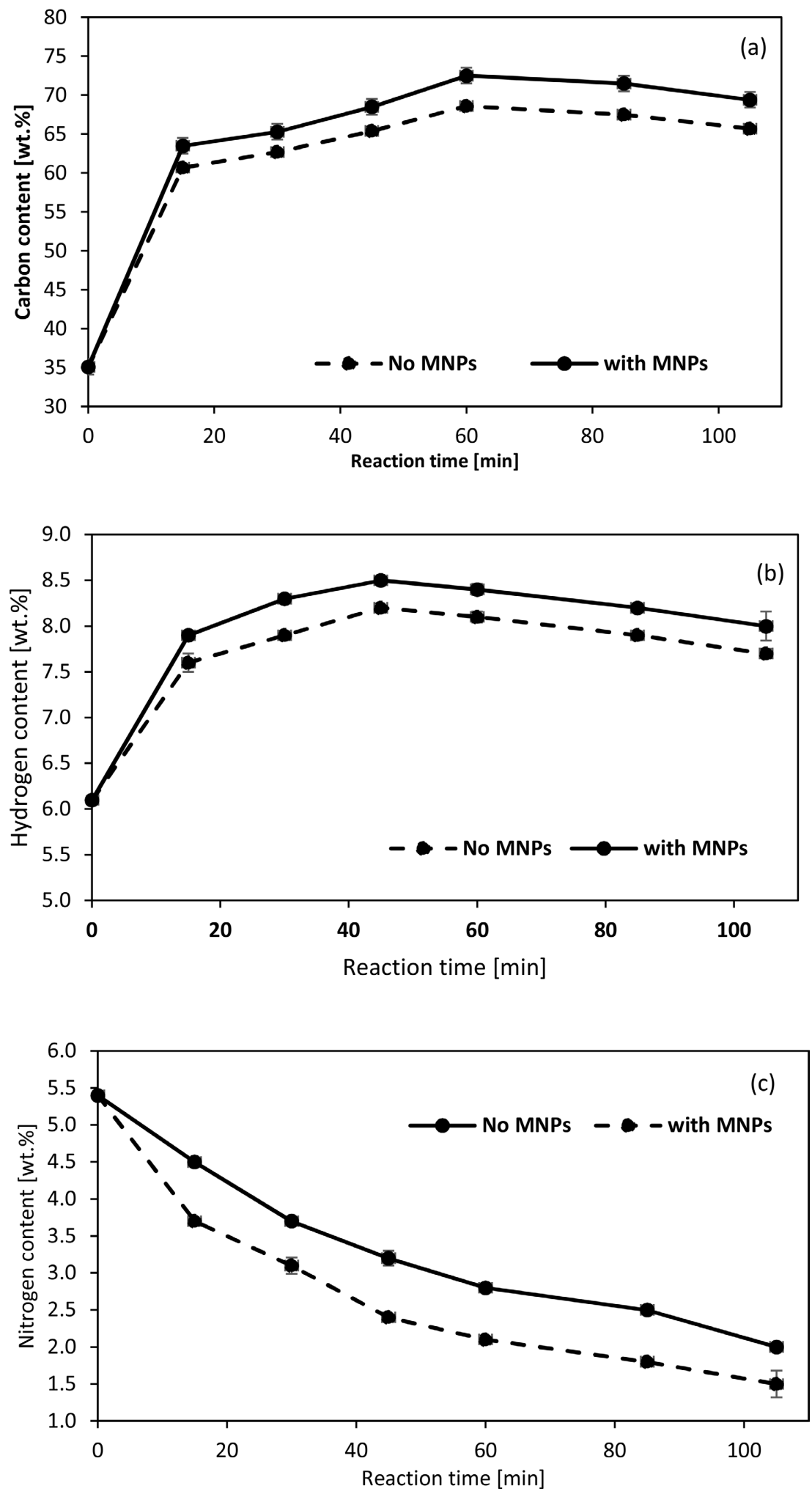

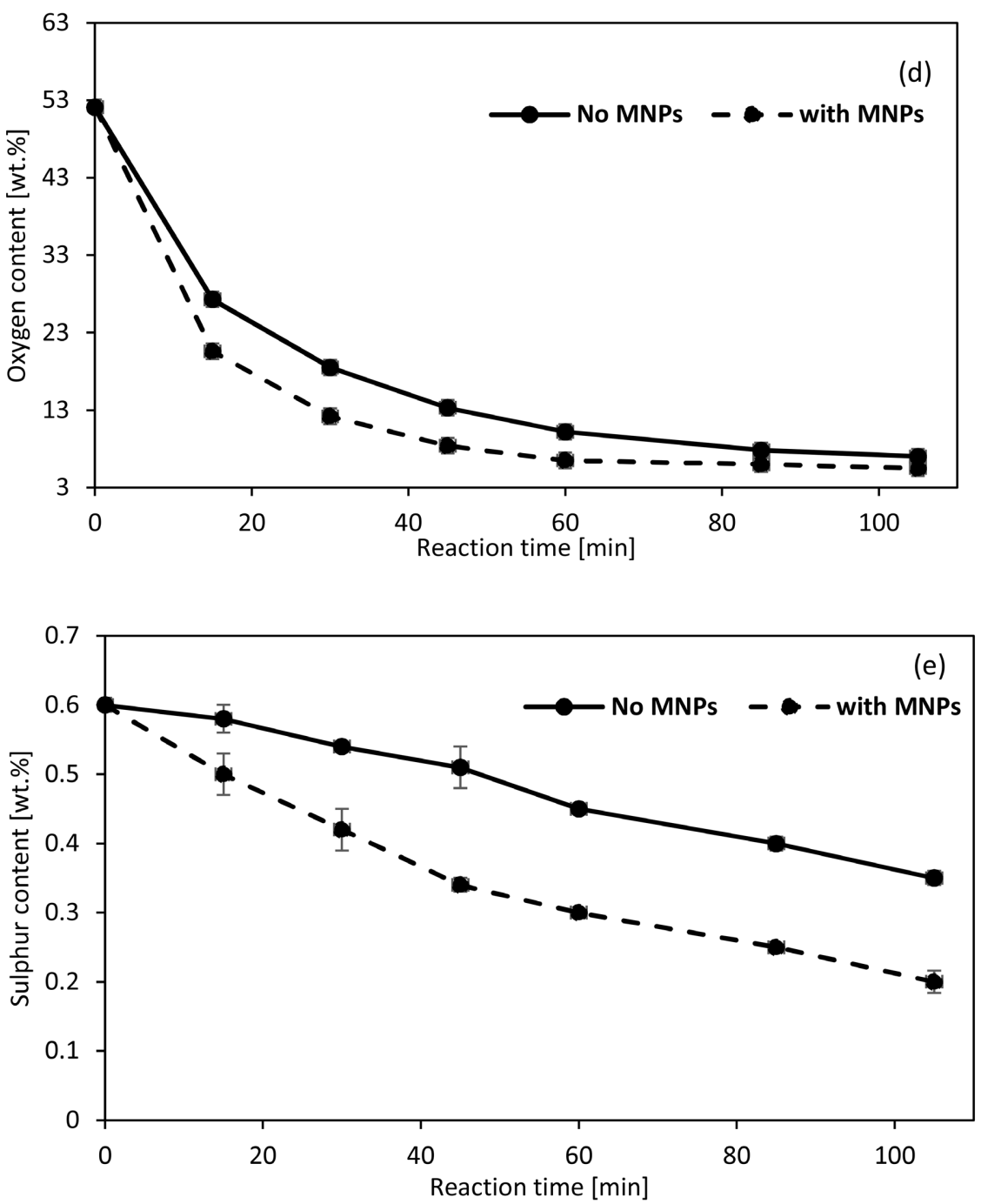

Figure 12. Elemental compositions of biocrude oil after HTL of water hyacinth at different reaction times at $320^{\circ} \mathrm{C}$ and at a ratio of MNPs to water hyacinth of 0.2. (a) Carbon content, (b) Hydrogen content, (c) Nitrogen content, (d) Oxygen content and (e) is Sulphur content at different reaction times. Reaction time 0 is when HTL has not been done yet therefore stands for the composition in the water hyacinth biomass feedstock.

amount of hydrogen in the biocrude oil was higher than that in the biomass from which it was derived (Table 1). The trend in hydrogen yield for catalyzed and uncatalyzed HTL was similar but catalyzed HTL registered higher yields (Table 1 and Figure 12(b)). For HTL in absence of MNPs (uncatalyzed), the amount of hydrogen increased from $6.1 \mathrm{wt} \%$ in the biomass feedstock to $7.6 \mathrm{wt} \%$ in biocrude oil after 15 minutes of HTL.

It increased further with increase in reaction time to a peak of $8.2 \mathrm{wt} \%$ after 45 minutes of HTL. Further increase in reaction time resulted in a gradual reduction in the hydrogen composition. For catalyzed HTL, the hydrogen composition increased from $6.1 \mathrm{wt} \%$ in biomass feedstock to $7.9 \mathrm{wt} \%$ after 15 minutes of HTL. The highest yield of hydrogen (8.5 wt\%) was observed after 45 minutes of HTL in presence of MNPs. 
These results show that HTL results in an increase in the hydrogen content of the biocrude oil compared to the biomass from which it was derived. In addition, more hydrogen yields can be realized when HTL is done in presence of MNPs. Furthermore, a reaction time of 45 minutes is required to achieve the highest hydrogen content in biocrude oil. It is also clear that MNPs played a catalytic role in favoring reactions that lead to an increased production of hydrogen from biomass. The nitrogen, oxygen and Sulphur content in the biocrude oil was lower than that in the biomass from which it was derived (Table 1).

There was a gradual reduction in the amount of nitrogen, oxygen and Sulphur with increase in reaction time for both catalyzed and uncatalyzed HTL. For catalyzed HTL, the N, O and S yield was much lower compared to uncatalyzed HTL. The nitrogen content in uncatalyzed HTL reduced from $5.4 \mathrm{wt} \%$ in the biomass feedstock to $4.5 \mathrm{wt} \%$ in biocrude oil after 15 minutes of reaction and to a lowest value of $2.0 \mathrm{wt} \%$ after 90 minutes of reaction. In uncatalyzed HTL, the nitrogen content reduced from $5.4 \mathrm{wt} \%$ in the biomass feedstock to $3.7 \mathrm{wt} \%$ after 15 minutes and then to its lowest value of $1.5 \mathrm{wt} \%$ after 90 minutes of reaction (Figure 12(c)). A similar reducing trend in nitrogen composition with time was also observed in literature during HTL of algae feedstocks [34] [35]. The reduction in nitrogen content with time is possibly due to its portioning into the aqueous phase in form of ammonia. The longer the reaction time the more nitrogen is lost into the aqueous phase, presence of MNPs seemed to fasten this process. These results show that HTL of biomass results in the reduction of the nitrogen content, more denitrogenation can be achieved with increased reaction time and that presence of MNPs can lead to increased removal of nitrogen from the biocrude oil. The MNPs potentially favor reaction which lead to increased denitrogenation of the biocrude oil. Denitrogenation is essential since it improves the fuels high heating value and reduces the release of harmful noxious gases (NOx) into the atmosphere. A high hetero atom content $(\mathrm{N}$ and $\mathrm{O})$ in the biofuels imparts undesirable fuel characteristics such as a high viscosity and acidity leading to a negative effect of the storage stability, combustion performance and economic value [19] [36] [37].

The oxygen composition reduced from $52.1 \mathrm{wt} \%$ in the biomass feedstock to $27.3 \mathrm{wt} \%$ in biocrude oil after 15 minutes of HTL (Figure 12(d)). Increase in reaction time resulted in a gradual reduction in the oxygen content up to its lowest value of $6.5 \mathrm{wt} \%$ after 90 minutes of HTL in absence of MNPs. For catalyzed HTL, the rate of deoxygenation was much higher, it reduced from 52.1 wt $\%$ in biomass feedstock to $20.6 \mathrm{wt} \%$ in biocrude oil after 15 minutes of HTL. Increase in reaction time resulted in further decrease in oxygen yield of biocrude oil to its lowest value of $5.5 \mathrm{wt} \%$ after 90 minutes of HTL. A similar trend in deoxygenation of biocrude oil with time was observed in HTL of algae [12] [34] [35]. Deoxygenation is potentially achieved through loss of oxygen into the gas phase in form of $\mathrm{CO}$ and $\mathrm{CO}_{2}$. The longer the liquefaction the more the loss of oxygen to the gas phase and hence the higher the rate of deoxygenation. The loss of oxygen is much higher when HTL is done in presence of MNPs which play a 
catalytic role in deoxygenation of the biocrude oil. These results reveal that deoxygenation of biocrude oils can be achieved by increasing the reaction time even in absence of a catalyst. But this comes at the expense of other essential elements like carbon and hydrogen since increase in reaction time beyond the optimum leads to a reduction in their percentage yield. HTL in presence of MNPs facilitates quicker deoxygenation and may be the solution to the above challenges. MNPs potentially played a catalytic role by favoring deoxygenation reactions resulting in an increased and faster removal of oxygen form biocrude oil. Biofuels generally contain a high oxygen content which is not desirable since it lowers the high heating value of the fuel. Removal of oxygen from biofuels increases their high heating value and energy recovery making them potentially competitive with petroleum derived fuels.

The Sulphur composition reduced from $0.6 \mathrm{wt} \%$ in biomass feedstock to 0.35 $\mathrm{wt} \%$ and $0.2 \mathrm{wt} \%$ in biocrude liquefied in presence and absence of MNPs respectively (Figure 12(e)). It is clear that there was increasing desulphurization with increase in reaction time. More Sulphur was removed when HTL was done in presence of MNPs. This confirms that MNPs played a catalytic role in favoring desulphurization reactions. A high Sulphur content in biofuel results in the production of dangerous gases such as Sulphur dioxide gas which lead to formation of acid rains.

For the HHV and ER, a similar trend with reaction time was observed for both catalyzed and uncatalyzed (Figure 13). The HHV increased steadily with increase in reaction time until a peak value was reached then it reduced gradually (Figure 13(a)). For catalyzed HTL, the HHV increased from $11.3 \mathrm{MJ} \cdot \mathrm{kg}^{-1}$ in the biomass feedstock to a peak of $35.5 \mathrm{MJ} / \mathrm{kg}^{-1}$ in the biocrude oil after $60 \mathrm{mi}$ nutes of liquefaction. Beyond this time, a reduction in HHV was observed. For HTL in absence of MNPs, the HHV increased from $11.3 \mathrm{MJ} / \mathrm{kg}^{-1}$ in the biomass feedstock to the highest value of $33.5 \mathrm{MJ} \cdot \mathrm{kg}^{-1}$ after 60 minutes of HTL. Beyond this a slight reduction in HHV was observed.

The increase in HHV can be attributed to the reduction in the heteroatom (N and O) content of the biocrude oil with time. Some studies have reported a reduction in the HHV values when there was a reduction in the $\mathrm{N}$ and $\mathrm{O}$ content of the biocrude oils [15] [19] [24]. Increase in HHV with time is also attributed to the increase in the $\mathrm{C}$ and $\mathrm{H}$ composition of biocrude oil with time as seen in Table 2. The slight reduction in HHV beyond the peak time of 60 minutes is attributed the reduction in the $\mathrm{C}$ and $\mathrm{H}$ content of the biocrude oil after $60 \mathrm{mi}$ nutes of HTL. From these results, it is evident that HTL in presence of MNPs resulted into a higher HHV than HTL in absence of MNPs. This is because, when HTL was done in presence of MNPs (catalyzed), a higher $\mathrm{C}$ and $\mathrm{H}$ content of biocrude oil was achieved. The higher the $\mathrm{C}$ and $\mathrm{H}$ content the higher HHV.

In addition, the low $\mathrm{N}$ and $\mathrm{O}$ content in biocrude oil from catalyzed HTL contributed to the increase in the HHV. The higher the $\mathrm{N}$ and $\mathrm{O}$ content of biocrude the lower the HHV. This combined effect led to biocrude produced in presence of MNPs having a higher HHV than biocrude produced in absence of 

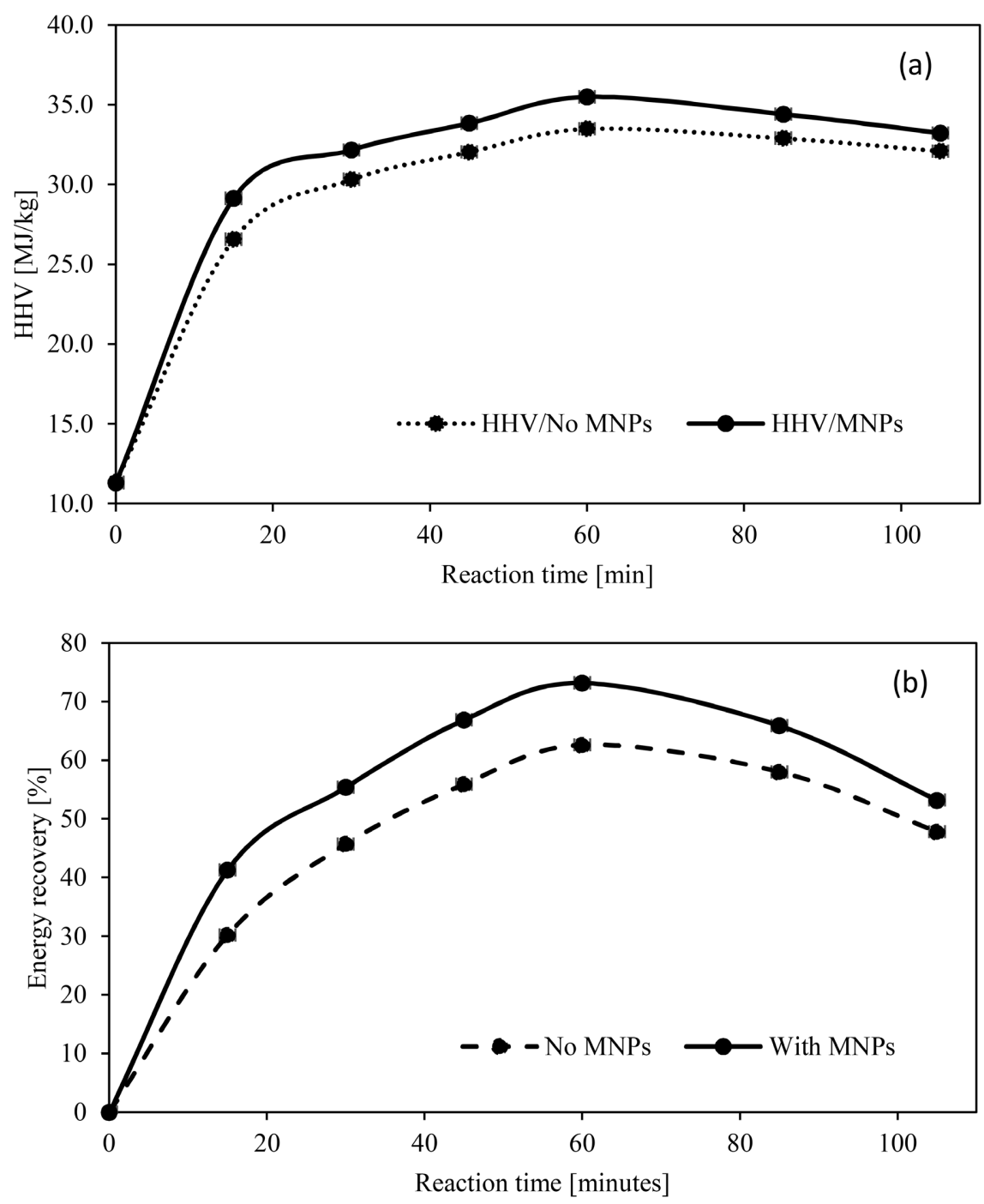

Figure 13. Trend in the (a) HHV and (b) energy recovery of biocrude oil after HTL in presence and absence of MNPs.

MNPs. For catalyzed HTL, the energy recovery increased steadily with reaction time up to the peak value of $73 \%$ after 60 minutes of reaction and then reduced gradually with increase in reaction time. A similar trend in ER was observed for both catalyzed and uncatalyzed HTL (Figure 13(b)).

The increase in ER with increasing reaction time is attributed to the steady increase in biocrude oil yields and HHVs between 0 to 60 minutes of reaction. The reduction in ER after 60 minutes of HTL, is attributed to the steady reduction in biocrude oil yields and HHVs beyond 60 minutes of HTL.

The $\mathrm{H} / \mathrm{C}, \mathrm{N} / \mathrm{C}$ and $\mathrm{O} / \mathrm{C}$ atomic ratios were also calculated and as reported in Table 1, there was a general reduction in atomic ratios with liquefaction time. The $\mathrm{O} / \mathrm{C}$ ratio indicates the polarity and abundance of polar oxygen containing surface functional groups in the biocrude oil. A higher $\mathrm{O} / \mathrm{C}$ ratio indicates that there are more polar functional groups in the oil and a lower $\mathrm{O} / \mathrm{C}$ ratio indicates that there are less polar functional groups in the oil or a reduction in polarity of 
the oil. This also implies that there is a shift in the adsorption mechanism from mainly ion exchange based to mainly physisorption or Van der Waals forces [38]. Since the Van der Waals forces are weaker, the sorption capacity within the oil drops. This is justified by the reduced viscosity of the biocrude oils at longer reaction times and at higher liquefaction temperatures. Longer liquefaction time is known to have a similar effect on biocrude oil as higher temperature liquefactions.

For the $\mathrm{H} / \mathrm{C}$ ratio, it is evident form Table 1 that there was a slight reduction in the $\mathrm{H} / \mathrm{C}$ ratio of the biocrude oil with increasing liquefaction time. It ranged between 1.4 to 1.5 for catalyzed HTL and between 1.3 to 1.49 for uncatalyzed $\mathrm{HTL}$. The H/C ratio indicates the aromaticity of the fuel, the higher the H/C ratio, the higher the energy efficiency of the fuel and the lower the $\mathrm{CO}_{2}$ emissions from its combustion. A very low $\mathrm{H} / \mathrm{C}$ ratio like in benzene 1:12 (0.08) implies that it is very difficult to burn the fuel without the production of carbon [37] [38]. Therefore, the lower the H/C ratio the lower the energy efficiency of the fuel and the higher the $\mathrm{CO}_{2}$ emissions. On the other hand, the higher the $\mathrm{H} / \mathrm{C}$ ratio the higher the energy efficiency of the fuel and the lower the $\mathrm{CO}_{2}$ emissions from its combustion.

The N/C ratio reduced steadily from 0.11 in the biomass feedstock to a lowest value of 0.03 in uncatalyzed biocrude oils and to 0.02 in catalyzed biocrude oils (Table 1). This is in agreement with the steady reduction in the $\mathrm{N}$ content of the biocrude oil with liquefaction time. The N/C ratio represents the amount of $\mathrm{N}$ and $\mathrm{C}$ in the bio-oil and is an important process parameter for the solid content in the oil. A high $\mathrm{N}$ content in the fuel is undesirable since it leads to production of NOx gases during combustion. These results show that HTL in presence of MNPs leads to an increased removal of $\mathrm{N}$ compounds from the biocrude oil hence reduction in the N/C ratio. This reduction is much higher when HTL was done in presence of MNPs.

\section{2) GC-MS Analysis of biocrude oil}

To further ascertain the identity and composition of the major compounds in the biocrude oil, and to confirm the effect of MNPs on biocrude composition, GC-MS analysis was done on the biocrude oil produced in presence and absence of MNPs. The identities of the major individual compounds extracted by DCM and their percentage relative areas were determined (Table 2, Figure 14 and Figure 15). Peaks in the GC-MS chromatogram with percentage relative area of less than $1 \%$ were not considered. The main compounds found in the biocrude oil were grouped under hydrocarbons, organic acids and esters (Figure 14). The hydrocarbons grouping consisted of the following compounds: undecane, dodecane, tetradecane, nonadecane, eicosane, heptadecane, octasane, 2 methyl-Pentacosane, Hexacosane, Hopane and Tetratriacontane (Table 2).

The organic acid grouping consisted of acetic acid and carbonic acid while the ester grouping consisted of Bis(2-ethylhexyl) phthalate. The hydrocarbon grouping was the most dominant and among the hydrocarbons, Pentacosane, 


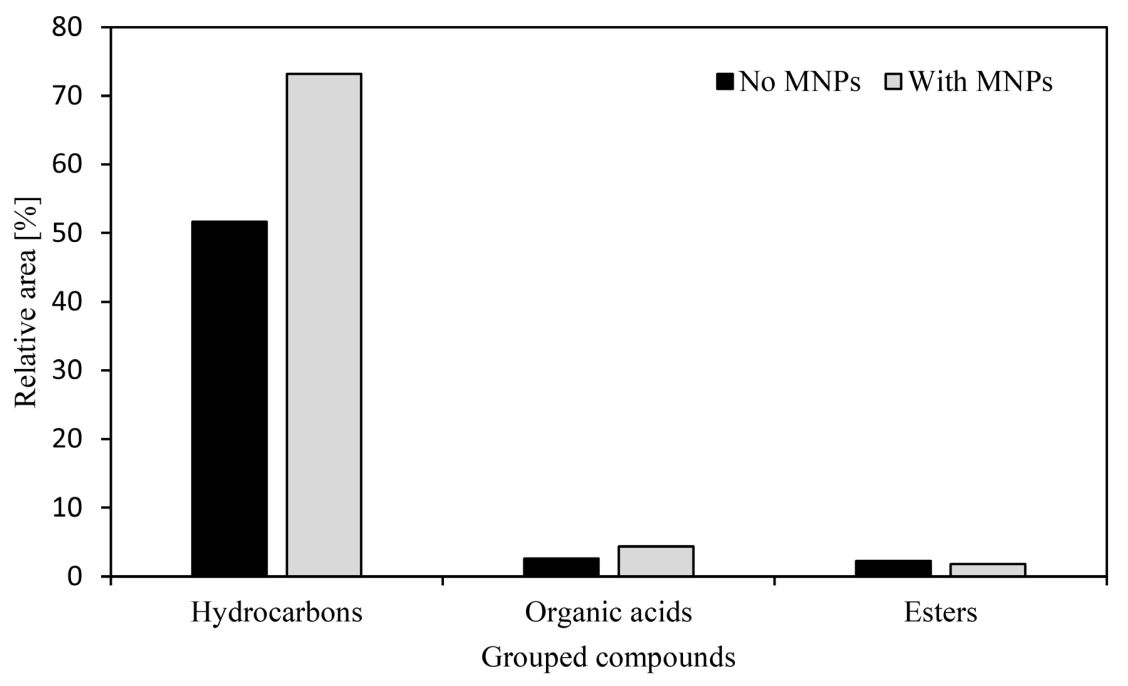

Figure 14. Distribution of the main grouped compounds in the biocrude oil after HTL of water hyacinth in presence and absence of MNPs at $320^{\circ} \mathrm{C}$ for 60 minutes.

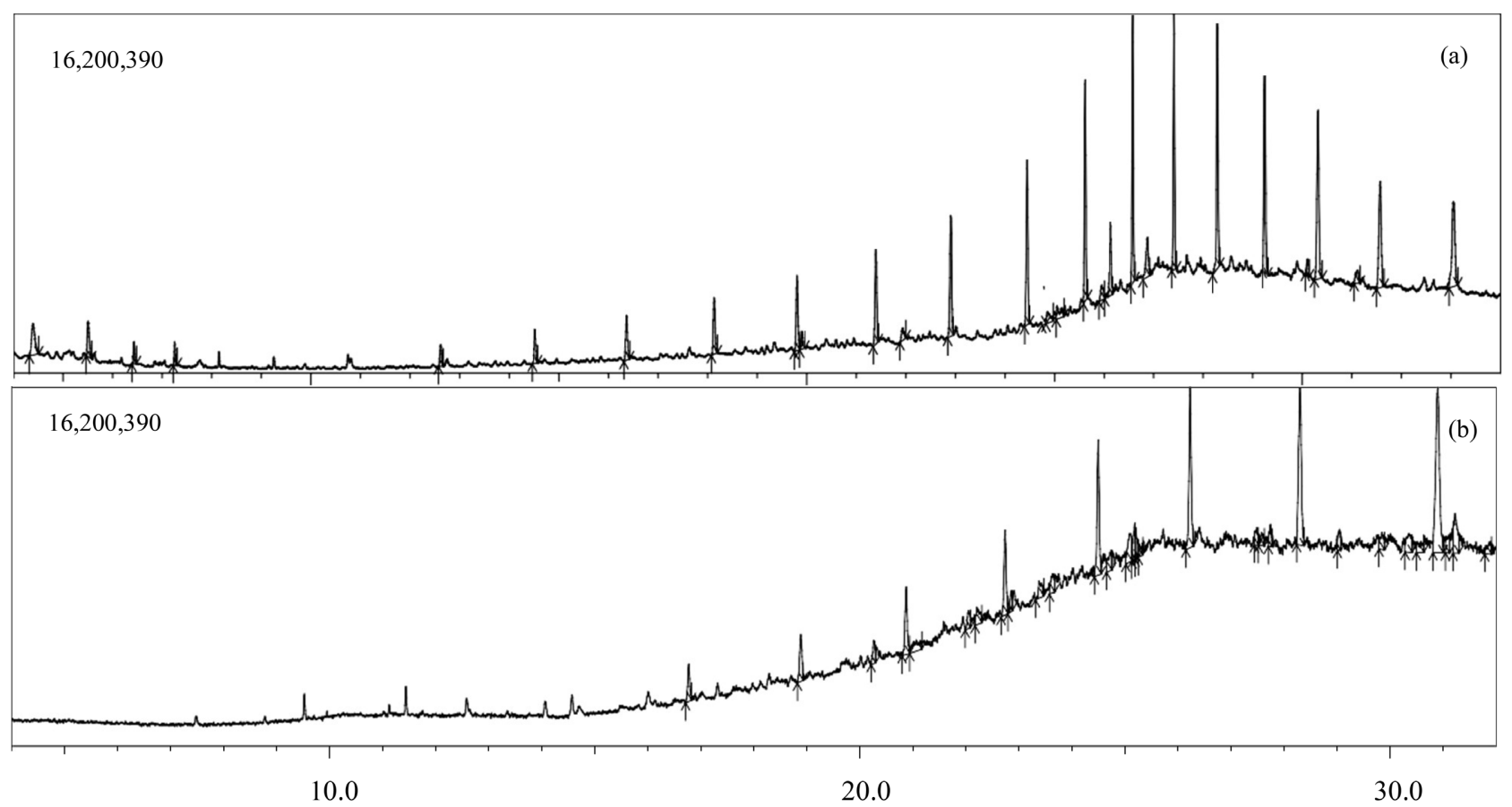

Figure 15. GC-MS Chromatogram of bio-crude oil from water hyacinth after $\mathrm{HTL}$ at $320^{\circ} \mathrm{C}$ and 60 minutes of reaction time. (a) HTL in absence of MNPs and (b) HTL in presence of MNPs.

eicosane and Hexacosane registered the highest compositions of $18.1 \%, 17.8 \%$ and $14.9 \%$ respectively for the biocrude oil produced in presence of MNPs. While for the biocrude oil produced in absence of MNPs, Hexacosane was the most abundant (13.4\%) followed by eicosane at $9.2 \%$. It is interesting to note that Pentacosane was below $1 \%$ for HTL in absence of MNPs while in presence of MNPs it was $18.1 \%$. This shows that MNPs may have played a catalytic role by favoring reaction that led to the decomposition of cellular components like carbohydrates and oils to produce more Pentacosane hence increasing the number 
Table 2. Major compounds identified in the GC-MS chromatogram of biocrude oil after $\mathrm{HTL}$ of water hyacinth in presence and absence of MNPs at $320^{\circ} \mathrm{C}$ for 60 minutes.

\begin{tabular}{|c|c|c|c|c|}
\hline \multirow{2}{*}{$\mathrm{RT}(\min )$} & \multirow{2}{*}{ Compound name } & \multicolumn{2}{|c|}{ Relative area (\%) } & \multirow{2}{*}{$\begin{array}{l}\text { Chemical } \\
\text { formular }\end{array}$} \\
\hline & & No MNPs & With MNPs & \\
\hline 4.39 & Undecane & 3.9 & * & $\mathrm{C}_{11} \mathrm{H}_{24}$ \\
\hline 5.501 & Dodecane & 3.5 & * & $\mathrm{C}_{12} \mathrm{H}_{26}$ \\
\hline 7.25 & Tetradecane & 1.0 & * & $\mathrm{C}_{14} \mathrm{H}_{30}$ \\
\hline 16.369 & Nonadecane & 6.4 & 13.0 & $\mathrm{C}_{19} \mathrm{H}_{40}$ \\
\hline 19.806 & Eicosane & 9.2 & 17.8 & $\mathrm{C}_{20} \mathrm{H}_{42}$ \\
\hline 19.905 & Acetic acid n-octadecyl ester & 1.2 & 1.48 & $\mathrm{C}_{20} \mathrm{H}_{40} \mathrm{O}_{2}$ \\
\hline 20.88 & Heptadecane, 2,6,10,15-tetramethyl- & * & 5.74 & $\mathrm{C}_{21} \mathrm{H}_{44}$ \\
\hline 21.941 & Octacosane, 2-methyl- & 2.7 & 1.27 & $\mathrm{C}_{29} \mathrm{H}_{60}$ \\
\hline 22.744 & Pentacosane & * & 18.1 & $\mathrm{C}_{25} \mathrm{H}_{52}$ \\
\hline 24.785 & Bis(2-ethylhexyl) phthalate & 2.2 & 1.8 & $\mathrm{C}_{24} \mathrm{H}_{38} \mathrm{O}_{4}$ \\
\hline 24.85 & Carbonic acid, eicosyl vinyl ester & 1.4 & 2.9 & $\mathrm{C}_{23} \mathrm{H}_{44} \mathrm{O}_{3}$ \\
\hline 28.282 & Hexacosane & 13.8 & 14.9 & $\mathrm{C}_{26} \mathrm{H}_{54}$ \\
\hline 28.282 & Hopane & 2.4 & 2.4 & $\mathrm{C}_{30} \mathrm{H}_{52}$ \\
\hline 33.048 & Tetratriacontane & 8.8 & * & $\mathrm{C}_{34} \mathrm{H}_{70}$ \\
\hline Total & & $56.5 \%$ & 79.4 & \\
\hline
\end{tabular}

*Very small peaks with area less than $1 \%$ were left out.

of hydrocarbons in the biocrude oils. The organic acids and esters were present in very small quantities, it is possible that during the HTL process, these may have been converted to hydrocarbons through decarboxylation reactions or other reaction pathways.

Just as in elemental analysis, GC-MS results also revealed a high hydrocarbon content, low composition of oxygenated compounds (acids and esters) and a very low composition of nitrogenated and Sulphur compounds to below detectable levels (below 1\%). These results show that HTL of water hyacinth biomass can increase the hydrocarbon composition and reduce the oxygenated, nitrogenated and Sulphur compounds in biocrude oil. In addition, further gains in hydrocarbon yields can be achieved when HTL is done in presence of MNPs.

\subsection{Recycling of MNPs}

After HTL of water hyacinth, the MNPs were largely deposited in the solid residue. These then were magnetically recovered as described in the methods section. The recovered MNPs were then tested for their suitability as HTL catalysts. The biocrude oil yields for the fresh and recycled MNPs was compared for up to five cycles (Figure 16). The recycled MNPs were effective in increasing the biocrude oil yield for up to five cycles. The biocrude yield started reducing in the $4^{\text {th }}$ 


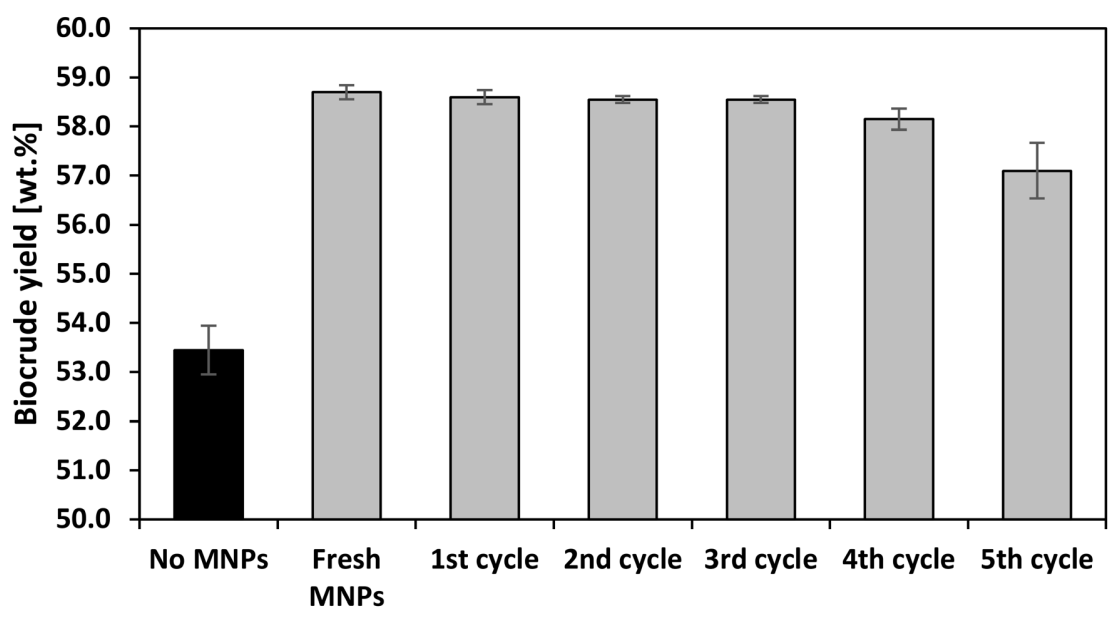

Figure 16. A comparison of biocrude oil yields for the fresh and recycled MNPs (up to 5 cycles). HTL of water hyacinth was done at $320^{\circ} \mathrm{C}$ for 60 minutes.

cycle and the $5^{\text {th }}$ cycle had the lowest biocrude yield (57.1 wt\%) for all the catalyzed runs. It is evident from Figure 16 that HTL in absence of MNPs had the lowest biocrude yield (53.5 wt\%). This further confirms that MNPs played a catalytic role in increasing the yield of biocrude oil in the hydrothermal liquefaction of water hyacinth. These results show that MNPs can be used as HTL catalysts to increase the biocrude oil yield and can be recycled magnetically for up to at least four cycles. Recycling of the catalyst can save on the cost of buying new catalysts for each batch hence making the process potentially economical.

\subsection{Conclusions}

This work reported for the first time the catalytic effect of MNPs in the hydrothermal liquefaction of water hyacinth. The MNPs were synthesized by the co-precipitation process and characterized using TEM, XRD and UV-Vis. The catalytic effect of the MNPs on the biocrude yield and composition was investigated. The effect of HTL process conditions on yield and chemical composition of biocrude oil was also investigated. It was observed that when HTL was done in presence of MNPs, the biocrude yield increased. The highest increase in biocrude yield (5.2 wt\%) was observed after 60 minutes of HTL at a mass ratio of MNPs to biomass of 0.2 , at a temperature of $320^{\circ} \mathrm{C}$ and at a mass ratio of biomass to water of 1:18. It was also observed that MNPs played a catalytic role in increasing the Carbon and Hydrogen content of biocrude oil and reducing the Nitrogen, Oxygen and Sulphur content of biocrude oil. Liquefactions in presence of MNPs resulted in a biocrude oil with a higher HHV and energy recovery. In addition, GC-MS analysis confirmed a higher composition of hydrocarbons in HTL reactions involving MNPs. Showing that MNPs played a catalytic role in favoring reaction that led to increased production of hydrocarbons. Furthermore, MNPs were successfully recycled and re-used to efficiently catalyze the HTL process for at least up to 5 cycles. Under the effect of HTL process conditions on biocrude yield and composition, it was observed that: increasing the 
reaction time resulted in a gradual increase in biocrude yield up to a peak yield and then a reduction in biocrude yield was observed with further liquefaction. In addition, increasing the mass ratio of MNPs to biomass, MNPs to water and increase in reaction temperature had similar effects of increasing the biocrude yield up to an optimum level and then a gradual reduction in yield with further liquefaction would be observed.

Therefore, we have demonstrated for the first time the application of magnetite nanoparticles in the catalytic HTL of water hyacinth. Resulting in increased biocrude yield, improved biocrude oil quality through removal of $\mathrm{N}, \mathrm{O}$ and $\mathrm{S}$ compounds and increased HHV and ER as well as increased H/C ratio. We also demonstrated that MNPs can be recycled in HTL of water hyacinth for up to 5 cycles culminating in a truly sustainable and potentially economical process. More work is being done in our research group to upgrade the biocrude oil to acceptable fuel standards.

\section{Acknowledgements}

This work was funded by the Government of the Republic of Uganda through the Makerere University Research and Innovations Fund (Grant number: MAKRIF/CONAS/004).

\section{Conflicts of Interest}

The authors declare no conflicts of interest regarding the publication of this paper.

\section{References}

[1] www.CO2.Earth (2021) Daily $\mathrm{CO}_{2}$. https://www.co2.earth/daily-co2

[2] Solomon, S., Manning, M., Marquis, M. and Qin, D. (2007) Climate Change 2007The Physical Science Basis: Working Group I Contribution to the Fourth Assessment Report of the IPCC. Vol. 4, Cambridge University Press, Cambridge.

[3] Patel, B., Tamburic, B., Zemichael, F.W., Dechatiwongse, P. and Hellgardt, K. (2012) Algal Biofuels: A Credible Prospective? International Scholarly Research Notices, 2012, Article ID: 631574. https://doi.org/10.5402/2012/631574

[4] Duan, P. and Savage, P.E. (2011) Catalytic Hydrotreatment of Crude Algal Bio-Oil in Supercritical Water. Applied Catalysis B: Environmental, 104, 136-143. https://doi.org/10.1016/j.apcatb.2011.02.020

[5] Chisti, Y. (2008) Biodiesel from Microalgae Beats Bioethanol. Trends in Biotechnology, 26, 126-131. https://doi.org/10.1016/j.tibtech.2007.12.002

[6] Safarik, I., Prochazkova, G., Pospiskova, K. and Branyik, T. (2016) Magnetically Modified Microalgae and Their Applications. Critical Reviews in Biotechnology, 36, 931-941. https://doi.org/10.3109/07388551.2015.1064085

[7] Peterson, A.A., Vogel, F., Lachance, R.P., Fröling, M., Antal Jr., M.J. and Tester, J.W. (2008) Thermochemical Biofuel Production in Hydrothermal Media: A Review of Sub- and Supercritical Water Technologies. Energy \& Environmental Science, 1, 32-65. https://doi.org/10.1039/b810100k

[8] Zou, S., Wu, Y., Yang, M., Li, C. and Tong, J. (2009) Thermochemical Catalytic Li- 
quefaction of the Marine Microalgae Dunaliella tertiolecta and Characterization of Bio-Oils. Energy \& Fuels, 23, 3753-3758. https://doi.org/10.1021/ef9000105

[9] Faeth, J.L. and Savage, P.E. (2016) Effects of Processing Conditions on Biocrude Yields from Fast Hydrothermal Liquefaction of Microalgae. Bioresource Technology, 206, 290-293. https://doi.org/10.1016/j.biortech.2016.01.115

[10] Rojas-Pérez, A., Diaz-Diestra, D., Frias-Flores, C.B., Beltran-Huarac, J., Das, K., Weiner, B.R., et al. (2015) Catalytic Effect of Ultrananocrystalline $\mathrm{Fe}_{3} \mathrm{O}_{4}$ on Algal Bio-Crude Production via HTL Process. Nanoscale, 7, 17664-17671. https://doi.org/10.1039/C5NR04404A

[11] Lee, A., Lewis, D., Kalaitzidis, T. and Ashman, P. (2016) Technical Issues in the Large-Scale Hydrothermal Liquefaction of Microalgal Biomass to Biocrude. Current Opinion in Biotechnology, 38, 85-89. https://doi.org/10.1016/j.copbio.2016.01.004

[12] Zhou, D., Zhang, L., Zhang, S., Fu, H. and Chen, J. (2010) Hydrothermal Liquefaction of Macroalgae Enteromorpha prolifera to Bio-Oil. Energy \& Fuels, 24, 4054-4061. https://doi.org/10.1021/ef100151h

[13] Akia, M., Yazdani, F., Motaee, E., Han, D. and Arandiyan, H. (2014) A Review on Conversion of Biomass to Biofuel by Nanocatalysts. Biofuel Research Journal, 1, 16-25. https://www.newvision.co.ug https://doi.org/10.18331/BRJ2015.1.1.5

[14] Egesa, D., Chuck, C.J. and Plucinski, P. (2018) Multifunctional Role of Magnetic Nanoparticles in Efficient Microalgae Separation and Catalytic Hydrothermal Liquefaction. ACS Sustainable Chemistry \& Engineering, 6, 991-999. https://doi.org/10.1021/acssuschemeng.7b03328

[15] Nallasivam, J., Eboibi, B., Isdepsky, A., Lavanya, M., Bhaskar, S. and Chinnasamy, S. (2020) Hydrothermal Liquefaction of Water Hyacinth (Eichhornia crassipes): Influence of Reaction Temperature on Product Yield, Carbon and Energy Recovery, and Hydrocarbon Species Distribution in Biocrude. Biomass Conversion and Biorefinery, 1-15. https://doi.org/10.1007/s13399-020-01032-1

[16] Phothisantikul, P.P., Tuanpusa, R., Nakashima, M., Charinpanitkul, T. and Matsumura, Y. (2013) Effect of $\mathrm{CH}_{3} \mathrm{COOH}$ and $\mathrm{K}_{2} \mathrm{CO}_{3}$ on Hydrothermal Pretreatment of Water Hyacinth (Eichhornia crassipes). Industrial \& Engineering Chemistry Research, 52, 5009-5015. https://doi.org/10.1021/ie302434w

[17] Patel, S.A. and Erickson, L. (1981) Estimation of Heats of Combustion of Biomass from Elemental Analysis Using Available Electron Concepts. Biotechnology and Bioengineering, 23, 2051-2067. https://doi.org/10.1002/bit.260230910

[18] Raikova, S., Smith-Baedorf, H., Bransgrove, R., Barlow, O., Santomauro, F., Wagner, J.L., et al. (2016) Assessing Hydrothermal Liquefaction for the Production of Bio-Oil and Enhanced Metal Recovery from Microalgae Cultivated on Acid Mine Drainage. Fuel Processing Technology, 142, 219-227.

https://doi.org/10.1016/j.fuproc.2015.10.017

[19] Hariani, P.L., Faizal, M. and Setiabudidaya, D. (2013) Synthesis and Properties of $\mathrm{Fe}_{3} \mathrm{O}_{4}$ Nanoparticles by Co-Precipitation Method to Removal Procion Dye. International Journal of Environmental Science and Development, 4, 336. https://doi.org/10.7763/IJESD.2013.V4.366

[20] Melo, A.F., Luz, R.A., Iost, R.M., Nantes, I.L. and Crespilho, F.N. (2013) Highly Stable Magnetite Modified with Chitosan, Ferrocene and Enzyme for Application in Magneto-Switchable Bioelectrocatalysis. Journal of the Brazilian Chemical Society, 24, 285-294. https://doi.org/10.5935/0103-5053.20130037

[21] de Caprariis, B., Bavasso, I., Bracciale, M.P., Damizia, M., De Filippis, P. and Scar- 
sella, M. (2019) Enhanced Bio-Crude Yield and Quality by Reductive Hydrothermal Liquefaction of Oak Wood Biomass: Effect of Iron Addition. Journal of Analytical and Applied Pyrolysis, 139, 123-130. https://doi.org/10.1016/j.jaap.2019.01.017

[22] Demirbaş, A. (2000) Mechanisms of Liquefaction and Pyrolysis Reactions of Biomass. Energy Conversion and Management, 41, 633-646.

https://doi.org/10.1016/S0196-8904(99)00130-2

[23] Biller, P. and Ross, A. (2011) Potential Yields and Properties of Oil from the Hydrothermal Liquefaction of Microalgae with Different Biochemical Content. Bioresource Technology, 102, 215-225. https://doi.org/10.1016/j.biortech.2010.06.028

[24] Minowa, T., Yokoyama, S.-Y., Kishimoto, M. and Okakura, T. (1995) Oil Production from Algal Cells of Dunaliella tertiolecta by Direct Thermochemical Liquefaction. Fuel, 74, 1735-1738. https://doi.org/10.1016/0016-2361(95)80001-X

[25] Yan, X., Ma, J., Wang, W., Zhao, Y. and Zhou, J. (2018) The Effect of Different Catalysts and Process Parameters on the Chemical Content of Bio-Oils from Hydrothermal Liquefaction of Sugarcane Bagasse. BioResources, 13, 997-1018. https://doi.org/10.15376/biores.13.1.997-1018

[26] Dadyburjor, D.B., Stewart, W., Stiller, A., Stinespring, C., Wann, J. and Zondlo, J. (1994) Disproportional Ferric Sulfide Catalysts for Coal Liquefaction. Energy \& Fuels, 8, 19-24. https://doi.org/10.1021/ef00043a003

[27] Beauchet, R., Monteil-Rivera, F. and Lavoie, J. (2012) Conversion of Lignin to Aromatic-Based Chemicals (L-chems) and Biofuels (L-fuels). Bioresource Technology, 121, 328-334. https://doi.org/10.1016/j.biortech.2012.06.061

[28] Abu El-Rub, Z., Bramer, E.A. and Brem, G. (2004) Review of Catalysts for Tar Elimination in Biomass Gasification Processes. Industrial \& Engineering Chemistry Research, 43, 6911-6919. https://doi.org/10.1021/ie0498403

[29] Toor, S.S., Rosendahl, L. and Rudolf, A. (2011) Hydrothermal Liquefaction of Biomass: A Review of Subcritical Water Technologies. Energy, 36, 2328-2342.

https://doi.org/10.1016/j.energy.2011.03.013

[30] Barreiro, D.L., Samorì, C., Terranella, G., Hornung, U., Kruse, A. and Prins, W. (2014) Assessing Microalgae Biorefinery Routes for the Production of Biofuels via Hydrothermal Liquefaction. Bioresource Technology, 174, 256-265.

https://doi.org/10.1016/j.biortech.2014.10.031

[31] Jin, F., Wang, Y., Zeng, X., Shen, Z. and Yao, G. (2014) Water under High Temperature and Pressure Conditions and Its Applications to Develop Green Technologies for Biomass Conversion. In: Application of Hydrothermal Reactions to Biomass Conversion, Springer, Berlin, 3-28. https://doi.org/10.1007/978-3-642-54458-3_1

[32] Boocock, D. and Sherman, K. (1985) Further Aspects of Powdered Poplar Wood Liquefaction by Aqueous Pyrolysis. The Canadian Journal of Chemical Engineering, 63, 627-633. https://doi.org/10.1002/cjce.5450630415

[33] Christensen, P.S., Peng, G.L., Vogel, F.D.R. and Iversen, B.B. (2014) Hydrothermal Liquefaction of the Microalgae Phaeodactylum tricornutum: Impact of Reaction Conditions on Product and Elemental Distribution. Energy \& Fuels, 28, 5792-5803. https://doi.org/10.1021/ef5012808

[34] Garcia Alba, L., Torri, C., Samorì, C., van der Spek, J., Fabbri, D., Kersten, S.R., et al. (2012) Hydrothermal Treatment (HTT) of Microalgae: Evaluation of the Process as Conversion Method in an Algae Biorefinery Concept. Energy \& Fuels, 26, 642-657. https://doi.org/10.1021/ef201415s

[35] Vardon, D.R., Sharma, B., Scott, J., Yu, G., Wang, Z., Schideman, L., et al. (2011) Chemical Properties of Biocrude Oil from the Hydrothermal Liquefaction of Spiru- 
lina algae, Swine Manure, and Digested Anaerobic Sludge. Bioresource Technology, 102, 8295-8303. https://doi.org/10.1016/j.biortech.2011.06.041

[36] Huber, G.W., Iborra, S. and Corma, A. (2006) Synthesis of Transportation Fuels from Biomass: Chemistry, Catalysts, and Engineering. Chemical Reviews, 106, 4044-4098. https://doi.org/10.1021/cr068360d

[37] Rafiq, M.K., Bachmann, R.T., Rafiq, M.T., Shang, Z., Joseph, S. and Long, R. (2016) Influence of Pyrolysis Temperature on Physico-Chemical Properties of Corn Stover (Zea mays L.) Biochar and Feasibility for Carbon Capture and Energy Balance. PLoS ONE, 11, e0156894. https://doi.org/10.1371/journal.pone.0156894

[38] Francis, W. and Peters, M.C. (2013) Fuels and Fuel Technology: A Summarized Manual. Elsevier, Amsterdam. 